US Army Corps of Engineers ${ }_{\circledast}$

Engineer Research and

Development Center

\title{
ERDC
}

\section{Penetration Modeling of Ultra-High Performance Concrete using Multiscale Meshfree Methods}

Paul A. Sparks, Jesse A. Sherburn, William F. Heard,
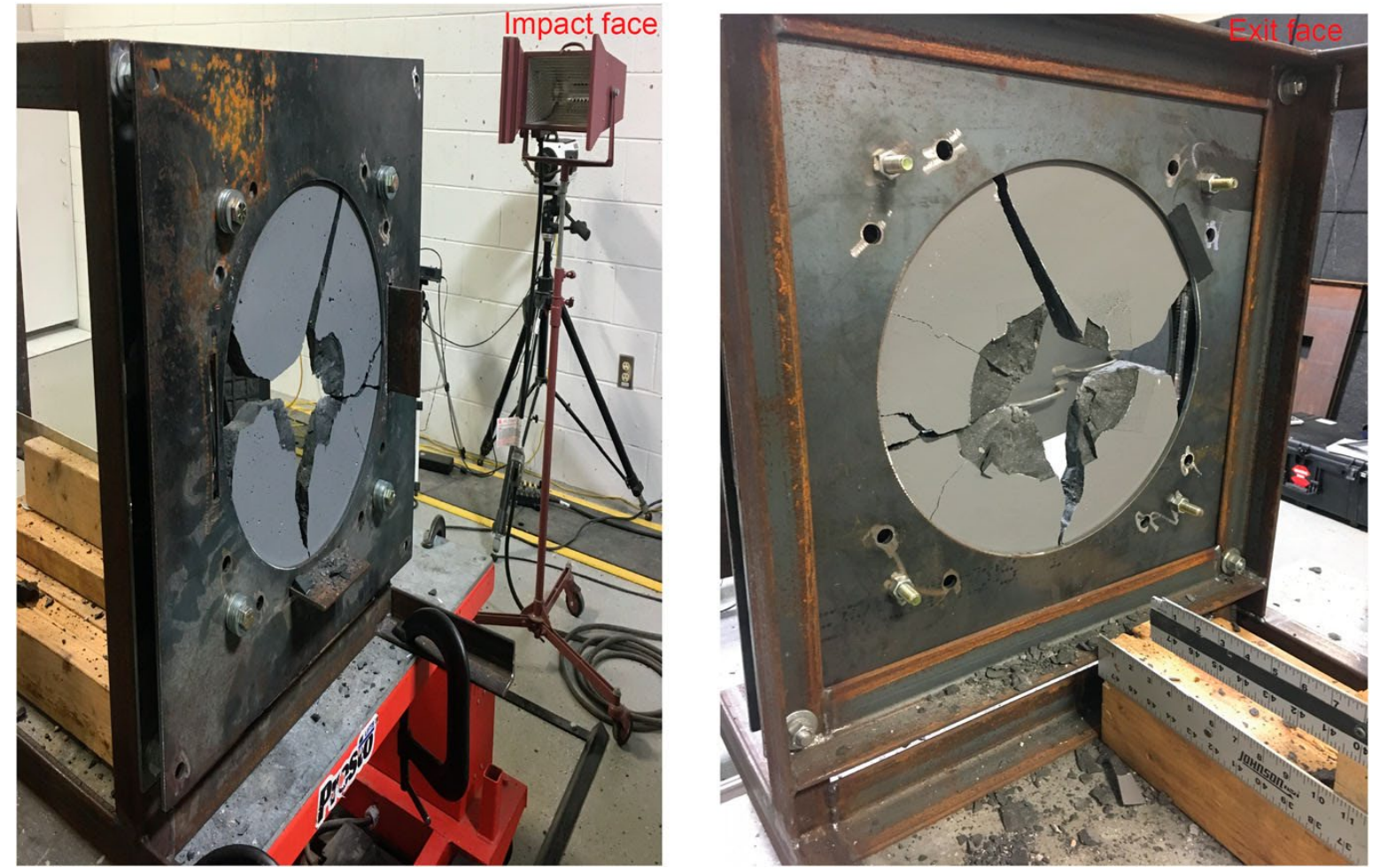
The U.S. Army Engineer Research and Development Center (ERDC) solves the nation's toughest engineering and environmental challenges. ERDC develops innovative solutions in civil and military engineering, geospatial sciences, water resources, and environmental sciences for the Army, the Department of Defense, civilian agencies, and our nation's public good. Find out more at www.erdc.usace.army.mil.

To search for other technical reports published by ERDC, visit the ERDC online library at https://erdclibrary.on.worldcat.org/discovery. 
ERDC/GSL MP-21-6

September 2021

\section{Penetration Modeling of Ultra-High Performance Concrete using Multiscale Meshfree Methods}

Paul A. Sparks, Jesse A. Sherburn, William F. Heard, and Brett A. Williams

Geotechnical and Structures Laboratory

U.S. Army Engineer Research and Development Center 3909 Halls Ferry Road

Vicksburg, MS 39180

Final report

Approved for public release; distribution is unlimited.

Prepared for U.S. Army Corps of Engineers

Washington, DC 20134

Under PE 61102, Project T22, "Material Modeling for Force Protection" 


\section{Preface}

The experiments described and the resulting data presented herein, unless otherwise noted, were funded under Program Element 61102, Task 02, Project Number T22 "Material Modeling for Force Protection," managed at the US Army Engineer Research and Development Center (ERDC).

The work was performed by the U.S. Army Engineer Research and Development Center, Geotechnical and Structures Laboratory (ERDC-GSL). At the time of publication of this paper, the Deputy Director of ERDC-GSL was Mr. Charles W. Ertle II was Deputy Director of ERDC-GSL, and the Director was Mr. Bartley P. Durst.

This article was originally published online in the International Journal of Numerical and Analytical Methods in Geomechanics on 10 October 2019.

The Commander of ERDC was COL Teresa A. Schlosser and the Director was Dr. David W. Pittman.

DISCLAIMER: The contents of this report are not to be used for advertising, publication, or promotional purposes. Citation of trade names does not constitute an official endorsement or approval of the use of such commercial products. All product names and trademarks cited are the property of their respective owners. The findings of this report are not to be construed as an official Department of the Army position unless so designated by other authorized documents. 


\title{
Penetration modeling of ultra-high performance concrete using multiscale meshfree methods
}

\begin{abstract}
Summary
Terminal ballistics of concrete is of extreme importance to the military and civil communities. Over the past few decades, ultra-high performance concrete

(UHPC) has been developed for various applications in the design of protective structures because UHPC has an enhanced ballistic resistance over conventional strength concrete. Developing predictive numerical models of UHPC subjected to penetration is critical in understanding the material's enhanced performance. This study employs the advanced fundamental concrete (AFC) model, and it will run inside the reproducing kernel particle method (RKPM)-based code known as the nonlinear meshfree analysis program (NMAP). NMAP is advantageous for modeling impact and penetration problems that exhibit extreme deformation and material fragmentation. A comprehensive experimental study was conducted to characterize the UHPC. The investigation consisted of fracture toughness testing, the utilization of nondestructive microcomputed tomography analysis, and lastly projectile penetration shots on the UHPC targets. To improve the accuracy of the model, a new scaled damage evolution law (SDEL) is employed within the microcrack informed damage model. During the homogenized macroscopic calculation, the corresponding microscopic cell needs to be dimensionally equivalent to the mesh dimension when the partial differential equation becomes ill posed and strain softening ensues. To ensure arbitrary mesh geometry for which the homogenized stress-strain curves are derived, a size scaling law is incorporated into the homogenized tensile damage evolution law. This ensures energy-bridging equivalence of the microscopic cell to the homogenized medium irrespective of arbitrary mesh geometry. Results of numerical investigations will be compared with results of penetration experiments.
\end{abstract}

\section{1 | INTRODUCTION}

Terminal ballistics of concrete is of extreme importance to the military and civil communities because it provides insight into designing defensive structures. Developing a better qualitative basis for the design of these defensive structures requires understanding the material proprieties of the target as well as the dynamics of the penetrator's interactions 
with the structure. The benefits of improving computational methodologies outweigh the cost; hence, these structures will protect personnel in theater as well as assets relating to national interest.

Developing capabilities to predict the penetration of a projectile impacting brittle materials has long roots stemming from World War II. Early research pioneered by White, ${ }^{1}$ and later by Kennedy, ${ }^{2}$ Backman and Goldsmith, ${ }^{3}$ and Ben-Dor et $\mathrm{al}^{4}$ focused on the amalgamation of experimental investigations in which analytical tools could be developed to predict ballistic limits of different target configurations subjected to penetration.

The advancement of these predicative capabilities is well documented for conventional and higher strength concrete impacted at lower striking velocity regimes. The subordnance $(25-500 \mathrm{~m} / \mathrm{s})$ and nominal ordnance $(500-1300 \mathrm{~m} / \mathrm{s})$ velocity regimes defined by Backman and Goldsmith ${ }^{3}$ account for the majority of projectile experiments shot with conventional laboratory guns. Luk and Forrestal ${ }^{5,6}$ conducted penetration experiments of spherical and ogive projectiles impacting 34.5-MPa semi-infinite and reinforced concretes at velocities between 300 and $830 \mathrm{~m} / \mathrm{s}$. Frew et al ${ }^{7}$ measured the penetration depths and deceleration of 13-kg ogive projectiles impacting 23-MPa compressive strength concrete targets cast in corrugated steel with striking velocities between 160 and $340 \mathrm{~m} / \mathrm{s}$. For higher strength concretes, Hanchak et $\mathrm{al}^{8}$ performed penetration experiments on concrete materials with higher unconfined compressive strengths (48 and $140 \mathrm{MPa}$ ) impacting thick concrete slabs with striking velocities between 300 and $1100 \mathrm{~m} / \mathrm{s}$.

The development of ultra-high performance concrete (UHPC) has fostered a need to understand and quantify the performance of the material when subjected to penetration. Máca et $\mathrm{al}^{9}$ studied the effect of impact behavior due to increasing fiber content for fiber reinforced UHPC. Wu et $\mathrm{al}^{10,11}$ investigated impact crater volumes and depths of penetration of UHPC formed from ogive penetrators with striking velocities ranging between 580 and $850 \mathrm{~m} / \mathrm{s}$ and 510 and $1320 \mathrm{~m} / \mathrm{s}$, respectively. Peng et $\mathrm{al}^{12}$ measured residual velocities of an ogive penetrator impacting UHPC reinforced with steel fibers at striking velocities between 250 and $480 \mathrm{~m} / \mathrm{s}$.

A search of the literature shows vast amounts of research focusing on conducting experiments with reinforced UHPC with an ogive penetrator or small caliber arms shot with striking velocities in the subordnance and nominal-ordnance regime. In conditions where fiber reinforcing materials are not readily available, the performance of the unreinforced UHPC needs to be assessed when impacted by small-arms projectiles. Backman and Goldman ${ }^{3}$ defined a third velocity regime beyond the nominal ordnance as the ultraordnance domain (1300-3000 m/s). Projectiles being shot at these higher velocity regimes impart a great amount of kinetic energy on a target, and density begins to dominate. Investigating the residual velocity of a projectile after perforating a protective structure in the ultraordnance regime is an active area of research. Experimental tests studying residual velocity of unreinforced UHPC subjected to a small arm, spherical projectile with striking velocities in the lower part of the ultraordnance velocity regime will be investigated.

Coupling the advancement of experimental penetration testing with increased computational power has led to an influx of hydrocodes and efficient computational algorithms in order to more efficiently study the penetration process. Mesh-based methods such as finite elements have been used to model penetration problems, but such methodologies employ element erosion (Johnson and Stryk ${ }^{13}$; Belytschko and $\mathrm{Lin}^{14}$ ) in the presence of extreme large deformation and damage. More recently, Rajput et $\mathrm{al}^{15}$ used finite element analysis to investigate the ballistic perforation of unreinforced and reinforced concrete impacted with striking velocities of 53 to $220 \mathrm{~m} / \mathrm{s}$. Zhang et al ${ }^{16}$ conducted finite element analyses of different projectiles, ie, ogive-nose, double-ogive-nose, and grooved-tapered, perforating concrete targets with striking velocities between 1000 and $1360 \mathrm{~m} / \mathrm{s}$ and validated experimental results. Smith et al ${ }^{17,18}$ used lattice discrete particle models to simulate the perforation of UHPC using a flat nose and ogive projectile with varying striking between 1000 and $3500 \mathrm{~m} / \mathrm{s}$.

In the context of meshfree methods, researchers have developed and employed different methods for modeling impact and penetration problems. Silling and Askari, ${ }^{19}$ and Diehl et $\mathrm{al}^{20}$ used peridynamics to model a spherical projectile impacting a brittle target with striking velocities between 35 and $200 \mathrm{~m} / \mathrm{s}$. Kala and Hušek, ${ }^{21}$ and Nordendale et $\mathrm{al}^{22}$ used smooth particle hydrodynamics (SPH) to model projectile impact of concrete targets with striking velocities of 500 and $1077 \mathrm{~m} / \mathrm{s}$, respectively. Chen et al, ${ }^{23,24}$ Chi et al, ${ }^{25}$ and Sherburn et al ${ }^{26,27}$ modeled concrete perforation problems utilizing reproducing kernel particle methods (RKPM). RKPM serves as a correction to SPH; the methodology does not need to employ complex numerical erosion of elements to SPH particles as seen in hybrid FEM and SPH methods, where material separation can naturally be captured during large deformation events. RKPM also does not rely on force functions that define the interaction between particles as seen in peridynamics.

In this paper, the advance fundamental concrete (AFC) model is employed to model the constitutive behavior of the UHPC. The AFC model is incorporated within the RKPM, and the overall solver is the nonlinear meshfree analysis program (NMAP). A series of ballistic penetration experiments performed at the US Army Engineer Research and Development Center (ERDC) studying UHPC materials being impacted by a spherical projectile at varying velocities was 
conducted. The experimental results are validated using NMAP to simulate the behavior of the UHPC at the microcontinuum and macro-continuum level. A new scaled damage evolution law (SDEL) is proposed to represent the homogenized response of the damage crack growth at the microstructural level. The scaled damage law is embedded into the AFC model, and numerical projectile penetration of the UHPC is conducted using NMAP to validate the experimental results. The calibrated model can be used to provide predictive capabilities for varying thicknesses of UHPC panels with an expanded velocity regime.

The remainder of this manuscript is as follows. The problem statement and the multiscale setting are described in Section 2. The energy bridging and damage model is described in Section 3. In Section 4, a brief review of RKPM theory is presented. Section 5 discusses the experimental validation study consisting of the microstructural and continuum level analysis. Conclusions are provided is Section 6.

\section{2 | PROBLEM STATEMENT AND MULTISCALE SETTING}

This study's goal is to model the inelastic deformation of projectile impact on a highly brittle, cementitious material. Consider a macroscopic domain $\Omega$ with boundary $\Gamma$ as shown in Figure 1. The domain of the microstructure $\Omega_{y}$ is composed of two or more constituents, eg, pores and surrounding matrix. The macrostructure and microstructure domains are parameterized by the position vectors $\mathbf{x}$ and $\mathbf{y}$, respectively. The ratio between the macroscopic and microscopic position vectors is related by a small positive scaling parameter, $\varepsilon$, such that $\mathbf{y}=\mathbf{x} / \varepsilon$.

The body force acting on the structure is assumed to be negligible as the body undergoes elastic static deformation; hence, the governing equations associated with the heterogeneous macroscopic boundary-valued problem are given as follows:

$$
\begin{gathered}
\nabla \cdot \sigma^{\varepsilon}=0 \text { in } \Omega \\
\sigma^{\varepsilon}=\mathbf{C}^{\varepsilon}: \mathbf{e}^{\varepsilon} \\
\mathbf{e}^{\varepsilon}=\frac{1}{2}\left(\nabla \otimes \boldsymbol{u}^{\varepsilon}+\boldsymbol{u}^{\varepsilon} \otimes \nabla\right)
\end{gathered}
$$

in which $\sigma^{\varepsilon}$ is the total macroscopic stress field, $\boldsymbol{u}^{\varepsilon}$ denotes the total displacement, $\mathbf{e}^{\varepsilon}$ the total strain field, and $\mathbf{C}^{\varepsilon}$ is the heterogeneous constitutive tensor of elastic moduli. The corresponding boundary conditions are

$$
\begin{gathered}
\sigma^{\varepsilon} \cdot \boldsymbol{n}=\boldsymbol{t} \text { on } \Gamma_{t} \\
\boldsymbol{u}^{\varepsilon}=\overline{\boldsymbol{u}} \text { on } \Gamma_{u} \\
\boldsymbol{\sigma}^{\varepsilon} \cdot \boldsymbol{n}=\boldsymbol{h} \text { on } \Gamma_{c}
\end{gathered}
$$

in which $\overline{\boldsymbol{u}}$ and $\boldsymbol{t}$ are the prescribed displacements and surface tractions on the boundaries $\Gamma_{t}$ and $\Gamma_{u}$, where $\Gamma_{t} \cup \Gamma_{u}=\Gamma$.

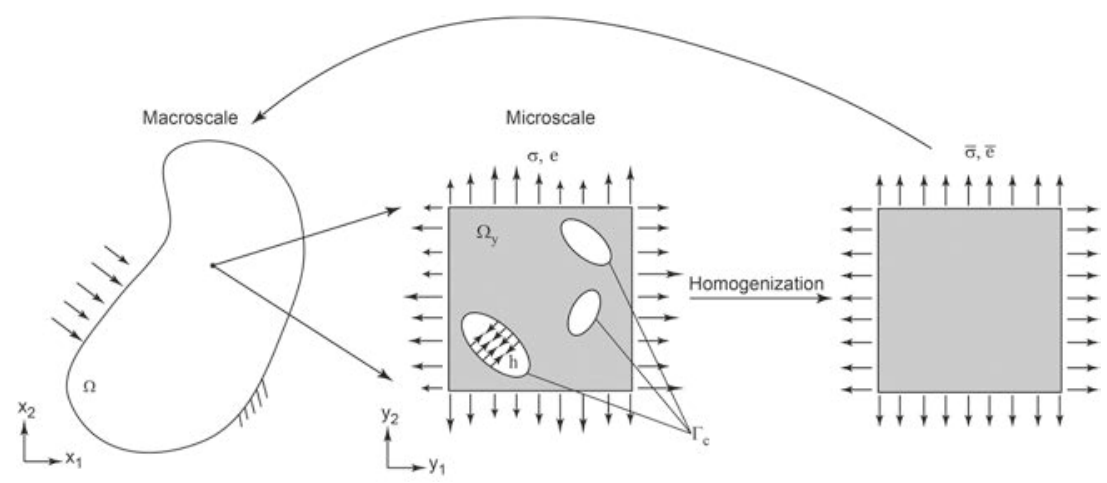

FIGURE 1 Energy bridging employed at the microscale to achieve the macroscale homogenized response 
At a given point within the macrostructural domain, a distribution of microcracks resides within the domain of the microstructure, $\Omega_{y}$; thus, the corresponding microcrack surfaces are denoted by $\Gamma_{c}$. $\boldsymbol{h}$ is the combination of these cracked surfaces, and $\boldsymbol{n}$ is the unit outward normal on the boundary $\Gamma_{c}$. The superscript $\varepsilon$ denotes the macroscopic and microscopic response fields that contribute to the total response field.

The spatial derivatives of an arbitrary response function, $f^{\varepsilon}$, are expressed in terms of the macroscopic and microscopic coordinates.

$$
\nabla_{x} f^{\varepsilon}(\boldsymbol{x}, \boldsymbol{y})=\nabla_{\boldsymbol{x}} f(\boldsymbol{x}, \boldsymbol{y})+\frac{1}{\varepsilon} \nabla_{\boldsymbol{y}} f^{\varepsilon}(\boldsymbol{x}, \boldsymbol{y})
$$

A two-scale asymptotic expansion is employed to formulate a coupled boundary value problem which relates the microscopic and macroscopic problem. The total displacement field is decomposed based on asymptotic expansion.

$$
\boldsymbol{u}^{\varepsilon}(\boldsymbol{x})=\sum_{i=0}^{\infty} \varepsilon^{i} \boldsymbol{u}^{[i]}(\boldsymbol{x}, \boldsymbol{y})
$$

The decomposition in Equation (8) is substituted into the governing equations, ie, Equations (1) to (6), and the expansion is performed; the details of the derivation and formal solutions have been reported in the literature (Guedes and $\mathrm{Kikuchi}^{28}$; Cheng ${ }^{29}$; Fish et $\mathrm{al}^{30}$; Ren et $\mathrm{al}^{31}$ ). Only significant results are detailed, and the resulting macroscopic/microscopic equations will be summarized. Collecting the $\boldsymbol{u}^{[0]}(\boldsymbol{x})$ terms and substituting in the relation of the tractions as a function of the homogenized stress and volume-averaging over the domain of the microscopic cell yields

$$
\sigma^{\varepsilon}=\frac{1}{V_{y}} \int_{\Omega_{y}} \sigma^{\varepsilon} d \Omega=\bar{\sigma}-\frac{1}{V_{y}} \oint_{\Gamma_{c}}\left(\mathbf{t}^{\varepsilon} \otimes \boldsymbol{x}\right) d s
$$

The homogenization of the equilibrium equations results in the homogenized stresses equating to the average stress in a cracked microscopic cell; hence,

$$
\bar{\sigma}=\sigma^{\varepsilon}
$$

where the Macaulay brackets are denoted as

$$
\cdot=\frac{1}{V_{y}} \int_{\Omega_{y}}(\cdot) d \Omega
$$

and $V_{y}$ is the volume of the microcell.

Performing asymptotic analysis of the original governing equations and collecting the terms that contribute to the microscale response naturally yield a microscale equilibrium equation defined over the domain of the microcell.

$$
\nabla_{\boldsymbol{y}} \cdot \mathbf{C}^{\varepsilon}: \nabla_{\boldsymbol{y}}^{\boldsymbol{s}} \chi \boldsymbol{y}=0 \text { in } \Omega_{\boldsymbol{y}}
$$

The boundary condition is expressed as

$$
\left[\mathbf{C}^{\varepsilon}: \nabla_{\boldsymbol{y}}^{\boldsymbol{s}} \chi \boldsymbol{y}: \nabla_{\boldsymbol{x}}^{\boldsymbol{s}} \boldsymbol{u}^{[0]} \boldsymbol{x}\right] \cdot \boldsymbol{n}=-\left[\mathbf{C}^{\varepsilon}: \nabla_{\boldsymbol{x}}^{\boldsymbol{s}} \boldsymbol{u}^{[0]} \boldsymbol{x}\right] \cdot \boldsymbol{n}+\boldsymbol{h} \text { on } \Gamma_{\boldsymbol{c}}
$$

The microcell problem results in solving for the third-order characteristic tensor $\chi(\boldsymbol{y})$. Hence, the fourth-order influence tensor $\mathbf{A}^{\varepsilon}$ represents the interscale relation between the properties of the cracked microstructure and the homogenized continua. $\mathbf{A}^{\varepsilon}$ can be obtained from $\chi(\boldsymbol{y})$ and has the following form.

$$
\mathrm{A}^{\varepsilon}=-\nabla_{y}^{s} \chi y
$$

The third-order characteristic tensor is computed numerically by utilizing the numerical solution of characteristic functions in the microcell, and this is computationally expensive; thus, energy bridging within the microcell is employed. 


\section{3 | ENERGY BRIDGING AND DAMAGE MODEL}

When the heterogeneous body is subjected to mechanical loads, microcracks develop, grow, and coalescence as the brittle solid exhibits a softening behavior and undergoes deformation. Damage can be defined as the progressive degradation of the heterogeneous body until failure has occurred. The relationship of the Helmholtz free energy (HFE), $\bar{\Psi}$ with damage is given as

$$
\bar{\Psi}=(1-d) \Psi_{0}^{\varepsilon}
$$

where, $d$ is scalar damage and subscript " 0 " denotes the initial elastic state. The microscopic free energy is the elastic strain energy defined as

$$
\Psi_{0}^{\varepsilon}=\frac{1}{2} \sigma^{\varepsilon}: \boldsymbol{e}^{\varepsilon}=\frac{1}{2} \boldsymbol{e}^{\varepsilon}: \boldsymbol{C}^{\varepsilon}: \boldsymbol{e}^{\varepsilon} .
$$

From the second law of thermodynamics, the following can be determined:

$$
\begin{gathered}
\bar{\sigma}=\frac{\partial \bar{\Psi}}{\partial \boldsymbol{e}^{\varepsilon}}=(1-d) \boldsymbol{C}^{\varepsilon}: \boldsymbol{e}^{\varepsilon}=(1-d) \boldsymbol{\sigma}^{\varepsilon} \\
\mathrm{Y}=\frac{\partial \bar{\Psi}}{\partial d} ; \dot{d}=\dot{g} \frac{\partial \bar{\Psi}}{\partial \mathrm{Y}}
\end{gathered}
$$

where, $\mathrm{Y}$ is the damage energy release rate and drives the damage evolution and $g$ is the consistency parameter. As mentioned above, the HFE of the cracked microcell, $\Psi_{0}^{\varepsilon}$, is defined as

$$
\Psi_{0}^{\varepsilon}=\frac{1}{2} \sigma^{\varepsilon}: \boldsymbol{e}^{\varepsilon} .
$$

In this manuscript, the evolution of damage of the microconstituents is modeled as a consequence of the microcrack propagation; hence, a microcrack informed damage model (MIDM) is employed to model this behavior. Ren et $\mathrm{al}^{31}$ introduced the relationship between the HFE of the damaged continuum and the averaged HFE of the microcell degraded by microcracks. Volume-averaging the microcell HFE and the respective microcell displacement field, $\boldsymbol{u}^{\varepsilon}$, over the domain of the microstructure, $\Omega_{y}$, yields the homogenized macroscale HFE

$$
\bar{\Psi}=\frac{1}{V_{y}}\left(\int_{\Omega_{y}} \Psi^{\varepsilon} d \Omega+\frac{1}{2} \int_{\Gamma_{c}} \boldsymbol{u}^{\varepsilon} \cdot \boldsymbol{h} d \Gamma\right)
$$

where, $V_{y}$ is the microcell volume. From Equation (20), the opening displacements corresponding to the microcracks are modeled explicitly, and the HFE is a function of the microcell stresses and strains. The microcell fracture is related to the macroscopic HFE by a two-scalar parameter damage model:

$$
\bar{\Psi}=\left(1-d^{+}\right) \Psi_{0}^{+}+\left(1-d^{-}\right) \Psi_{0}^{-} .
$$

The two damage variables describe the degradation of the tensile, $d^{+}$and shear, $d^{-}$failure surface. The free energy potential, $\Psi_{0}$, corresponds to an undamaged microcell which has the potential to do work. As the microcell is loaded and damage accumulates, the free energy available to do work is reduced. The Clausius-Duhem inequality of irreversible thermodynamics can be derived from Equation (21); thus,

$$
\Psi_{0}^{ \pm}=Y^{ \pm}
$$

where, $Y^{ \pm}$are the damage energy release rate. Combining Equations (21) and (22) and taking the derivative of the microcell HFE with respect to the Y yields

$$
d^{+}=1-\frac{\partial \bar{\Psi}}{\partial Y^{+}} \approx 1-\frac{\bar{\Psi}}{Y^{+}} .
$$


For the remainder of the paper, the damage law evaluated is with respect to the tensile contribution $d^{+}$. A summary of the key features of the MIDM has been discussed; for in-depth derivations, refer to Ren et al. ${ }^{31}$ The next section will detail how $d^{+}$is computed.

\section{1 | Scaled damage evolution law (SDEL)}

It is well documented in the literature that conducting a mesh refinement study on a domain and resolving the successive mesh spacing from a coarse discretization to a finer while utilizing a local damage model leads to mesh dependency (Pijaudier-Cabot et $\mathrm{al}^{32}$; Bazant and Jirasek ${ }^{33}$; Jirasek ${ }^{34}$ ). Lin et $\mathrm{al}^{35}$ showed the size effect due to employing the microcracked informed damage law and validated the analyses with quasistatic numerical investigations. The fracture cohesive law employed within the MIDM is independent of a length scale; hence, larger microcells with imperfections are statistically more likely to fail. Conducting similar numerical investigations using meshfree methods and subjecting different geometric length microcells to kinematically admissible loading based on homogenization theory reveals that the energy dissipation reduces as refinement of the microcells when calculating the HFE.

The damage evolution function is only valid for the microcell for which the homogenized energy bridging was calculated; hence, utilizing a different discretization (or particle spacing) requires calculating a new HFE for the subsequent microcell. Without incorporating a characteristic length into the damage law, the solutions will not correctly capture the energy within the softening region of the microcells, and the solution will exhibit this mesh dependency.

To accurately capture the HFE within the microcell and alleviate this size dependency, a general modified sigmoid functional is applied to capture the nonlinear damage evolution form. The modified damage sigmoid incorporates a characteristic length scaling parameter $\lambda$ and represents an approximation of the evolution of damage within the matrix constituent phase. The SDEL is a function of $\lambda$ and $\overline{\mathrm{e}}$ and is given by

$$
d^{+} \lambda \mathrm{e}^{-}=\frac{1}{1+v e^{-\lambda \chi \mathrm{e}^{-}-\mathrm{e}^{-}}}
$$

The dimensionless characteristic length scaling parameter $\lambda$ is

$$
\lambda=\frac{l_{\text {mic }}}{l_{\text {mac }}}
$$

where $l_{m i c}$ and $l_{m a c}$ are the microscopic and macroscopic length parameters, respectively. The damage initiation strain $\overline{\mathrm{e}}_{i}$ utilizes the same initiation term from Lin et $\mathrm{a}^{35}$; the idea was first inspired by the Bazant, ${ }^{36}$ size effect law; it resembles a similar form and is expressed as

$$
\overline{\mathrm{e}}_{i}=\frac{A}{\sqrt{1+a \lambda}}
$$

where $a, A, v$, and $\chi$ are constants.

\subsection{Identification of optimal damage evolution function parameters}

The identification of the optimal set of constants that correspond to the microcell-dependent SDEL is posed as an optimization problem. Let $\boldsymbol{s}$ consist of the constants defined in the SDEL; hence, $\boldsymbol{s}=\{a, A, v, \chi\}$. The problem of identifying the optimal set of constants, $s^{*}$, that satisfies the following optimization problem is defined as

$$
F\left(\boldsymbol{s}^{*}\right)=\min _{\boldsymbol{s} \in \boldsymbol{s}^{i}} \sum_{k=1}^{n_{\text {load }}}\left\|d_{r e f}^{+(k)}(\lambda, \overline{\mathrm{e}})-d^{+}{ }_{\boldsymbol{s}}^{(k)}(\lambda, \overline{\mathrm{e}} ; \boldsymbol{s})\right\|_{2}
$$

where $\|\cdot\|_{(2)}$ denotes the $\mathrm{L}_{2}$ norm. $d_{r e f}^{+(k)}$ and ${d^{+}}_{\boldsymbol{s}}^{(k)}$ are the damage response computed from energy bridging of the HFE and the damage response from the SDEL subjected to load case, $k . s^{i}$ is the set of all possible feasible constants such that $\boldsymbol{s}^{1}=\left\{a^{1}, A^{1}, v^{1}, \chi^{1}\right\}, \boldsymbol{s}^{2}=\left\{a^{2}, A^{2}, v^{2}, \chi^{2}\right\}, \ldots, \boldsymbol{s}^{n}=\left\{a^{n}, A^{n}, v^{n}, \chi^{n}\right\}$. The details of the microcell characterization and analyses are discussed in Section 5. For brevity, when conducting the microcell analyses, the porosity of the microcell was informed by the micro-CT analyses. The reference microcell damage response, $d_{r e f}^{+(k)}$ corresponding to the 
microstructure which was degraded by microcracks, is calculated during the microstructural analysis. The HFE of the damaged microcell is homogenized over the cell and that produces a highly nonlinear damage response vs homogenized strain curve from the energy bridging. The $d_{s}^{+(k)}$ is the SDEL calculated from Equation (24), which is a modified sigmoid that approximates the nonlinear damage evolution form using the optimal set of constants $\boldsymbol{s}^{*}$. Equation (27) is evaluated using a nonlinear least squared algorithm to identify $\boldsymbol{s}^{*}$.

The optimal set of constants resulting from the analysis ensures that the errors associated with the optimal parameter set are minimized with respect to the HFE from the subsequent microcells. The proposed SDEL is incorporated into the MIDM that is embedded into a modified version of the AFC model. ${ }^{37}$

\section{4 | RKPM MICROCELL ANALYSIS}

In this study, RKPM will be used to conduct the microscopic cell analysis. The results of the microcell solution employ energy bridging to achieve the homogenized response for the tensile damage evolution function as described in Section 3.

Within the RKPM framework, first proposed by Liu et $\mathrm{al}^{38}$ and Chen et $\mathrm{al}^{39}$ the RK approximation function $\boldsymbol{u}^{h}(\boldsymbol{X})$ is modified and constructed by the product of the kernel function $\phi_{a}\left(\boldsymbol{X}-\boldsymbol{X}_{I}\right)$ with compact support and a correction function that enforces the reproducibility conditions of the basis. The function has the following form:

$$
\boldsymbol{u}^{h}(\boldsymbol{X}, t)=\sum_{I \in N}\left\{\sum_{|\alpha|=0}^{n}\left(\boldsymbol{X}-\boldsymbol{X}_{I}\right)^{\alpha} b_{\alpha}(\boldsymbol{X})\right\} \phi_{a}\left(\boldsymbol{X}-\boldsymbol{X}_{I}\right) \boldsymbol{d}_{I}(t)=\sum_{I \in N} \Psi_{I}(\boldsymbol{X}) \boldsymbol{d}_{I}(t)
$$

where $\Psi_{I}(\boldsymbol{X})$ is the RK shape function corresponding to the $I^{\text {th }}$ node, $N$ is the number of nodes, $\boldsymbol{d}_{I}(t)$ is the coefficient that approximates the displacements, and $\boldsymbol{X}$ is with respect to the reference material coordinate system. The term $\left\{\sum_{|\alpha|=0}^{n} \boldsymbol{X}-\boldsymbol{X}_{I}{ }^{\alpha}\right\}$ is the set of monomial basis functions, and the coefficients $\left\{b_{\alpha}(\boldsymbol{X})\right\}$ are determined by enforcing the following reproducing conditions.

$$
\sum_{I \in N} \Psi_{I}(\boldsymbol{X}) \boldsymbol{X}_{I}^{\alpha}=\boldsymbol{X}^{\alpha}
$$

where $|\alpha|=0,1, \cdots, n$. Computing $\left\{b_{\alpha}(\boldsymbol{X})\right\}$ from Equation (25), the RK shape functions are obtained as

$$
\Psi_{I}(\boldsymbol{X})=\boldsymbol{H}^{T}\left(\boldsymbol{X}-\boldsymbol{X}_{I}\right) \boldsymbol{M}^{-1}(\boldsymbol{X}) \boldsymbol{H}(0) \phi_{a}\left(\boldsymbol{X}-\boldsymbol{X}_{I}\right)
$$

where $\boldsymbol{H}^{T}\left(\boldsymbol{X}-\boldsymbol{X}_{I}\right)$ is the corresponding row vector of $\left\{\sum_{|\alpha|=0}^{n} \boldsymbol{X}-\boldsymbol{X}_{I}{ }^{\alpha}\right\}$ containing all the basis functions, and $\boldsymbol{M}(\boldsymbol{X})$ is a moment matrix.

The above discussion provides a basic overview of the RKPM framework, and the details were neglected for brevity. The RKPM microcell analysis also employs the enrichment of the RKPM functions as detailed in the literature (Fleming et $\mathrm{al}^{40}$; Moes and Belytschko ${ }^{41}$; Ren et $\mathrm{al}^{31}$ ).

\section{5 | VALIDATION STUDY}

In this study, the correlation between the pore characteristics, ie, pore size, shape, and size distribution, and the material response of the UHPC was studied using both experimental and numerical methodologies.

The material under consideration is a UHPC, which was developed at the US Army Engineer Research and Development Center (ERDC) by O'Neil, ${ }^{42}$ and later characterized by Williams et al. ${ }^{43}$ It stems from a family of UHPCs and is distinguished by its superior mechanical properties. From the unconfined compression tests, the material without steel fiber reinforcements has an average strength of $210 \mathrm{MPa}$. The UHPC is sensitive to minor changes in the constituent material; thus, careful precision during the mix design must be ensured to achieve the desired properties. Unlike conventional concrete that includes coarse aggregates, the UHPC is composed of fine aggregates with its largest microconstituent limited to a maximum size of $0.6 \mathrm{~mm}$ and has a water-to-cement ratio restricted to 0.21 , lower than the conventional concrete ratio of 0.40 .

Figure 2 illustrates the general framework of the procedure for incorporating multiscale material information at the microstructural scale into the continuum multiscale analysis. After laboratory tests at the continuum level are 

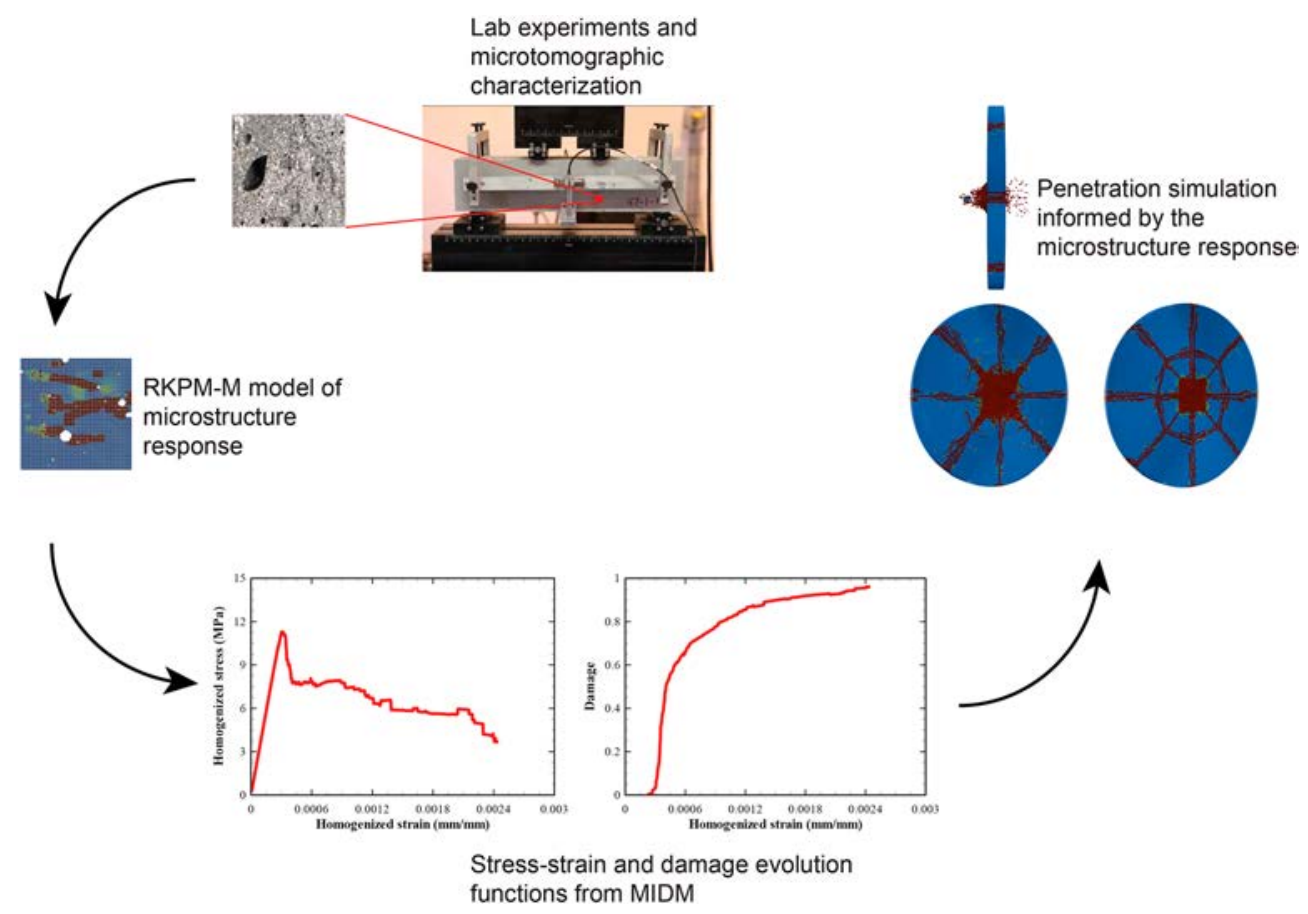

FIGURE 2 A general overview of multiscale material modeling framework [Colour figure can be viewed at wileyonlinelibrary.com]

conducted, local meshfree RKPM microstructural calculations are performed to model the propagation of microcracks within the microcell. Local response fields, ie, stress and strain, are homogenized, and the damage evolution scaling law is employed to alleviate numerical size effect. The homogenized damage evolution scaling law in tandem with the modified AFC model helps to govern the UHPC response during the penetration modeling at the continuum level. In the following sections, detailed descriptions of these processes will be discussed.

\section{1 | Microstructural characterization}

After the UHPC was mixed and placed, specimens were cured according to the process described by Williams et al. ${ }^{43}$ To characterize the microstructure of the UHPC, high-resolution micro-CT scanning was conducted using a SkyScan 1173 high-energy X-ray system. The 19-mm diameter by $38-\mathrm{mm}$ length cores were taken from a large beam cast to investigate the material's microstructure. From the cored specimen, it was possible to achieve a high resolution of 11.02- $\mu \mathrm{m}$ pixel. The imaging conditions used were $130 \mathrm{kV}$ with a current of $60 \mu \mathrm{A}$. Additionally, the filter was $0.25-\mathrm{mm}$-thick brass with a rotational step of $0.15^{\circ}$. Frame averaging was 15 , and the random movement was 15 .

From the cored UHPC sample, the pore distributions were examined using micro-CT. Using a pixel size in the 11.02 micrometer range, the micro-CT produces a set of 2D X-ray projection images of the sample. These images were converted to cross-sectional images using NRecon software. Image processing techniques are utilized in CTAn to convert the cross-sectional CT images into binary images. The fully reconstructed 3D dataset is obtained by stacking the converted cross-sectional images. For this study, the investigation focused on two distinct phases of the UHPC, ie, the matrix and pores. Therefore, when the 2D cross-sectional images were re-stacked or re-assembled throughout the model volume, 3D microstructural features were identified as either belonging to the matrix or a pore (void). This process yields a very large database of every individual microstructural feature throughout the volume with individual pore volumes spanning more than three orders of magnitude with the maximum pore volume of $1.5 \mathrm{~mm}^{3}$. This large dataset consists of key features from the sample, eg, location and volume of all the voids, number of voids listed individually, shape factors of the voids, aggregates, associated volumes, etc. The resolution of all the other microstructural features are all assumed to exist in the matrix phase. A single micro-CT cross-section image is shown in Figure 3.

Probabilistic and quantitative methods were used to characterize the pore size distribution. The data were analyzed based on pore sizes greater than $77 \mu \mathrm{m}$ in diameter but less than $1.3 \mathrm{~mm}$. The underlying void sizes closely resemble a four-parameter (4P) Burr distribution. The values corresponding to the 4P Burr distribution are given below in Table 1. 


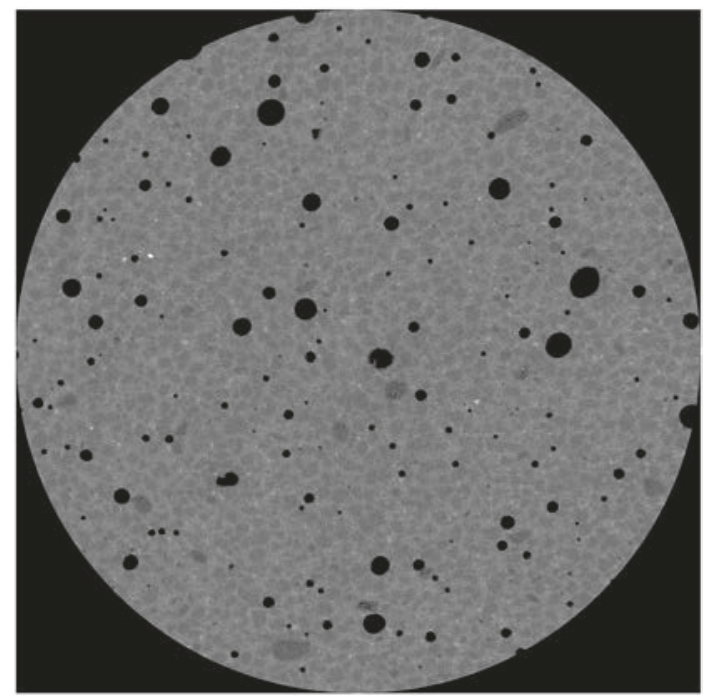

FIGURE 3 Micro-CT cross-sectional image of the UHPC

TABLE 1 Best fit for individual UHPC pore sizes corresponding to four-parameter Burr distribution

\begin{tabular}{lr} 
Parameter & Value \\
$k$ & 3.9313 \\
$\alpha$ & 1.1698 \\
$\beta$ & 290.43 \\
$\gamma$ & 77 \\
\hline
\end{tabular}

The probability density function (PDF) is given as

$$
f(x)=\frac{a k\left(\frac{x-\gamma}{\beta}\right)^{\alpha-1}}{\beta\left(1+\left(\frac{x-\gamma}{\beta}\right)^{\alpha}\right)^{k+1}} ; k, \alpha, \beta, \gamma>0
$$

where, $\mathrm{k}$ and $\alpha$ are continuous shape parameters, $\beta$ is a continuous scale parameter, and $\gamma$ is a continuous location parameter.

Figure 4 illustrates the PDF of the 4P Burr distribution with a histogram showing the relative frequency of pores. In this figure, pore sizes are represented by an "equivalent sphere diameter" (ESD), which is the diameter of an idealized sphere having the same volume as the actual measured pore volume. The histogram plot provides insight into the frequency of smaller pores residing in the microstructure as compared with larger size pores on the mm-length scale. The UHPC has superior mechanical properties due to its low porosity and refined pore size distribution; however, the low water-to-cement ratio required to achieve these mechanical properties can sometimes result in poor workability resulting in infrequent but large size pores that are detrimental to the materials' microstructure. The 4P Burr distribution appeared to capture this materials characteristic. For the distribution analysis shown in Figure 4, a Chi-squared goodness of fit test returned a $P$ value of 0.04896 indicating that the collected data reasonably match the $4 \mathrm{P}$ Burr distribution.

To quantify the cross-sectional heterogeneity of the UHPC's microstructure, the cross-sectional porosity is computed for different size microcells. Percent porosity is the measure of all the empty space or void space in the microstructure and is defined as

$$
\% \text { Porosity }=\frac{\sum_{i=1}^{n} A_{\text {void }}}{A_{\text {cell }}} \times 100
$$

where $n$ is the total number of random ESD's, $A_{\text {void }}$ is the cumulative area $\left(\mu \mathrm{m}^{2}\right)$ of the voids, and $A_{c e l l}$ is the area of the 


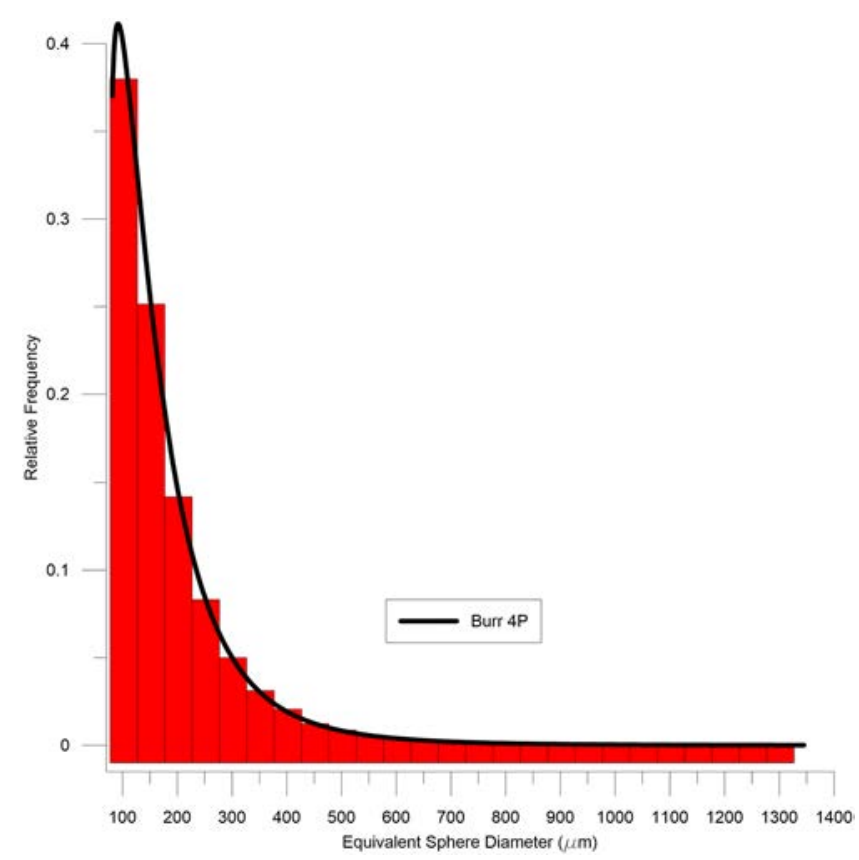

FIGURE 4 Four-parameter Burr distribution [Colour figure can be viewed at wileyonlinelibrary.com]

microscopic cell. Figure 4 shows that approximately $98.6 \%$ of the pores have an ESD less than $600 \mu \mathrm{m}$. These pore sizes are on the order of the maximum aggregate constituent size. Hence, the remaining $1.4 \%$ of pores within the microstructure of the UHPC are larger than the constituent size.

\section{2 | Microcell analysis}

Numerical validation studies of the microcell were conducted to evaluate the performance of the proposed SDEL compared with the reference MIDM damage evolution law calculated from the HFE. The microcell analysis consists of modeling a two-phase media (matrix and pores) in which the microstructural pore-size distribution reflects the crosssectional porosity generated from the micro-CT analysis. Figure 5 depicts the geometry and statistically representative pore size distribution of four varying size microcells. As mentioned previously, the UHPC's microstructure consists of densely packed constituent materials and has low water-to-cement ratio; hence, the material has a low porosity. The micro-CT scans confirmed the relative relation of the pores, and the surrounding UHPC matrix material indeed have a low porosity; therefore, all of the microcells are assumed to consist of the same average area porosity of 3.4\%. Holding the average area porosity constant allows for the size effect of the microcell to be fully investigated without varying the $\%$ porosity because the UHPC has a low porosity relative to conventional concretes.

Figure 5A-D shows four distinct microcell sizes ranging from $3.0 \times 3.0,4.5 \times 4.5,5.0 \times 5.0$, and $6.5 \times 6.5 \mathrm{~mm}^{2}$. The different microcell sizes correspond to the particle spacing in the macroscale discretized domain. This variation is selected in order to investigate the size effect. As previously defined in Section 3.1, $\lambda$ is the dimensionless characteristic length scaling parameter that normalizes the microcell size length to the length of the macroscopic domain. Hence, $l_{\text {mic }}$ corresponding to the microcell sizes are $l_{\text {mic }}=3.0,4.5,5.0$, and $6.5 \mathrm{~mm}$ and $l_{\text {mac }}$ is the diameter of the macroscopic UHPC panel as shown in Figure 2, where $l_{\text {mac }}=406.4 \mathrm{~mm}$.

Before the calculating the SDEL, local response parameters, ie, stress and strain, must be computed prior to energy bridging. The microcell analysis was performed utilizing nonlinear meshfree analysis program-micro (NMAP-M) that is a two-dimensional RKPM-based code. The research code is a joint effort by the ERDC and University of California San Diego-University of California Los Angeles (UCSD-UCLA) to efficiently model the evolution of crack growth within a microcell based on fracture mechanics. Ren et $\mathrm{al}^{31}$ used enriched $\mathrm{RK}$ particle methods (RKPM) to investigate microcracks informed damage (MIDM) based models. Lin et $\mathrm{al}^{35}$ furthered the works of Ren by investigating MIDM for material failure using stochastic microstructures. The damage evolution law is obtained from HFE from the 


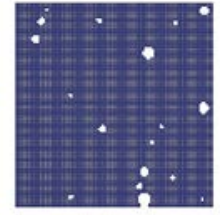

(A)

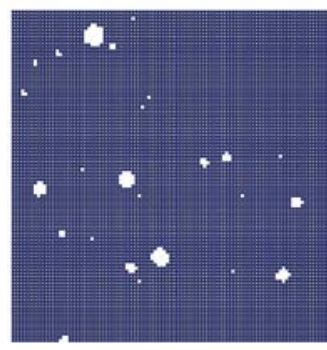

(C)

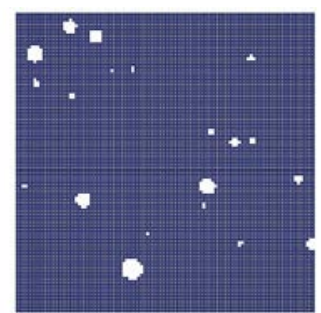

(B)

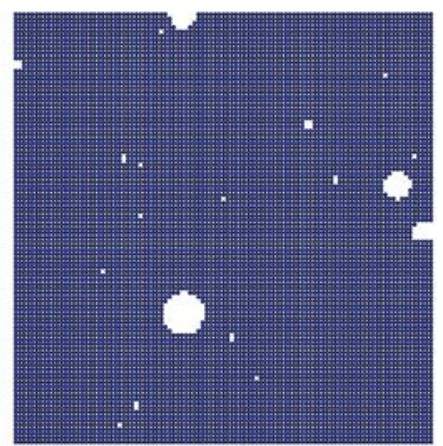

(D)

FIGURE 5 UHPC microcell geometry with average area porosity of $3.4 \%$ corresponding to $l_{\text {mic }}=$ (A) 3.0 , (B) 4.5 , (C) 5.0 , and (D) $6.5 \mathrm{~mm}$ [Colour figure can be viewed at wileyonlinelibrary.com]

microcrack and the continuum. This energy bridging method is based on fracture mechanics and exploits the evolution of the microstructural strain field as the driver of the damage evolution function. The constitutive response for UHPC is modeled using a linear-elastic cohesive law that linearly softens when the peak tensile strength is exceeded. Table 2 gives a summary of the key microcell parameters utilized in the calculation of the local response parameters.

A series of quasi static and dynamic laboratory experiments were conducted at the ERDC to investigate the macroscopic material behavior of the UHPC. Table 3 summarizes the types of mechanical property tests conducted at the ERDC. The experiments consisted of hydrostatic compression, triaxial compression, unconfined direct pull, and uniaxial load/constant volume tests. The quasi static results were documented by Williams et $\mathrm{al}^{43}$ and the dynamic unconfined compressive strength, and the resulting dynamic increase factor, were characterized by Martin et al. ${ }^{44}$ The UHPC fracture energy was obtained by Sherburn et $\mathrm{l}^{45}$ using the three-point notched beam test developed by Hillerborg et al. ${ }^{46} \mathrm{~A}$ mode I crack initiated at the notch and propagated through the beam, and the resulting fracture energy was determined from the crack tip opening displacement (CTOD). From the physical test, macroscale constitutive parameters, ie, elastic modulus, Poisson's ratio, peak tensile strength, and fracture energy, were identified and documented for use during the numerical validation study.

The microscopic tensile strength of the UHPC was determined by conducting a series of local numerical microcell calculations in order to calibrate the microstructural peak tensile stress to the overall average macroscopic value. For each of the microcells illustrated in Figure 5, the average porosity of the cell was held constant while spatially varying the pore locations and sizes. The pore sizes corresponding to each of the microcell sizes were based on a random sampling of the 4P Burr distribution shown in Figure 4. Microcrack seeds were inserted at possible microcrack nucleation

TABLE 2 Cohesive law parameters for the microcell calculations

\section{Parameter}

Young's modulus (MPa)

Poisson's ratio

Tensile strength (MPa)

Fracture energy $(\mathrm{N} / \mathrm{m})$
Value

44296 
TABLE 3 Summary of mechanical test performed on UHPC known as Cor-Tuf

\section{Mechanical test}

Hydrostatic compression, triaxial compression, unconfined compression, direct pull, and uniaxial strain

Williams et $\mathrm{al}^{43}$

Dynamic unconfined compressive strength

Martin et $\mathrm{al}^{44}$

Fracture energy

Sherburn et $\mathrm{al}^{45}$

sites around each void in the microcell. A series of 25 random microcell geometries with randomly varying $\mathrm{x}$ and y pore locations was generated for each microcell. The resulting microcell geometries were subjected to uniaxial tension, and a sampling of the resulting Mode I cracked regions are shown in Figure 6A-D. As the material undergoes deformation, the microcracks develop, grow, and coalescence. Once the local strain exceeds the critical threshold, a microcrack begins to grow, and the microcell begins losing its load carrying capacity.

For each of the microcell sizes, 25 microcell simulations were conducted to calculate the overall average response. Figure 7A-D shows the pre-peak and post-peak stress-strain variation corresponding to the different $l_{\text {mic }}$ sizes for the microcell simulation. Figure 8 shows the average homogenized stress and strain curves corresponding to each microcell size without the variation. The post-peak is very soft for tension and does not fail abruptly as seen with most brittle materials. The material constituents in this particular UHPC allow for a softer response due to the varying constituent sizes which spans multiple length scales. The small residual stress is expected for concrete under tension, and it also portrays the correct trend which is the peak strength decreases for larger microcells and the residual stress decreases as well. This strength reduction is due to the increased presence of flaws which are expected in larger microcell sizes. The average damage and homogenized strain curves using energy bridging homogenization, as discussed in Section 3, are shown in Figure 9. Figures 8 and 9 display the influence of the size effect and mesh dependency due to the damage law not scaling with the dimensions of the microcell size. This size effect is further demonstrated when the nominal strength of each of the cell sizes is plotted against $\lambda$ and fitted to the size effect law (Bazant ${ }^{36}$ ) as shown in Figure 10. The different $l_{\text {mic }}$ sizes for the microcells were based off the pore sizes determined from the micro-CT analyses. Analyses presented in this paper reflect pore sizes that the micro-CT could detect. Due to limitations with the micro-CT, it is hard

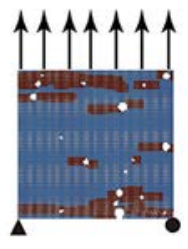

(A)

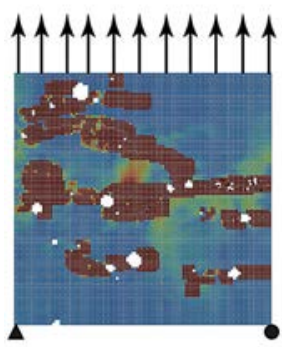

(C)

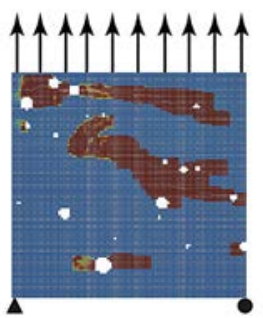

(B)

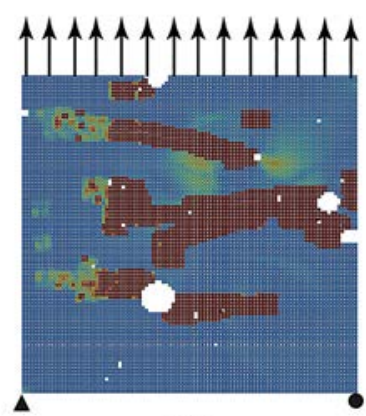

(D)

FIGURE 6 Principal strain cracks of spatially random generated pore location and size with average area porosity of $3.4 \%$ corresponding to $l_{\text {mic }}=$ (A) 3.0, (B) 4.5, (C) 5.0, and (D) $6.5 \mathrm{~mm}$ [Colour figure can be viewed at wileyonlinelibrary.com] 


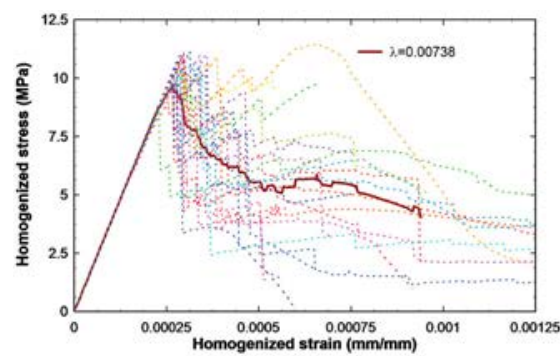

(A)

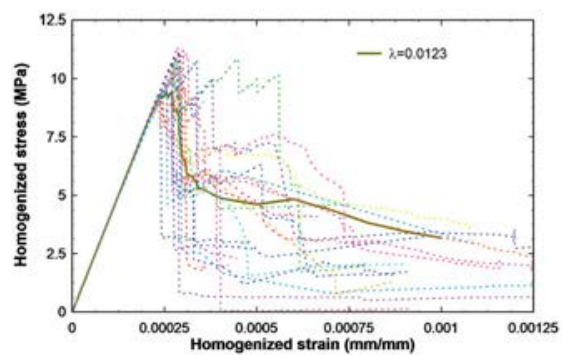

(C)

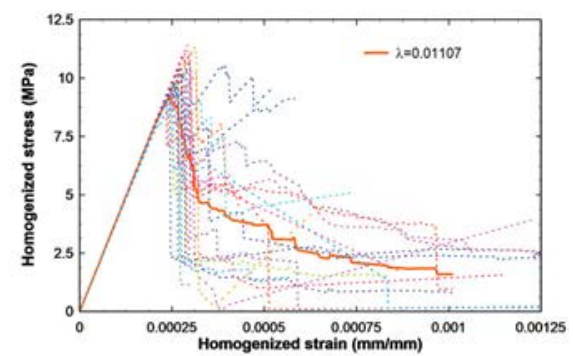

(B)

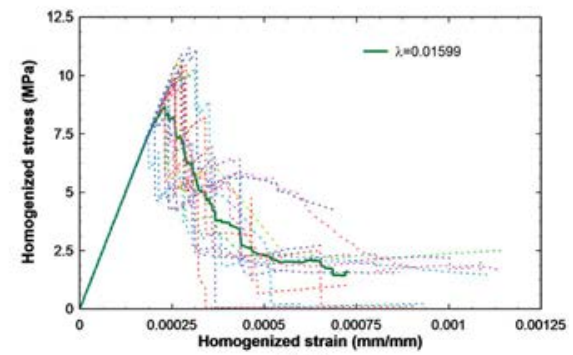

(D)
FIGURE 7 Homogenized stress-strain curves and averaged homogenized stressstrain curves with average area porosity of $3.4 \%$ corresponding to $l_{m i c}=$ (A) 3.0, (B) 4.5 , (C) 5.0, and (D) $6.5 \mathrm{~mm}$ [Colour figure can be viewed at wileyonlinelibrary.com]

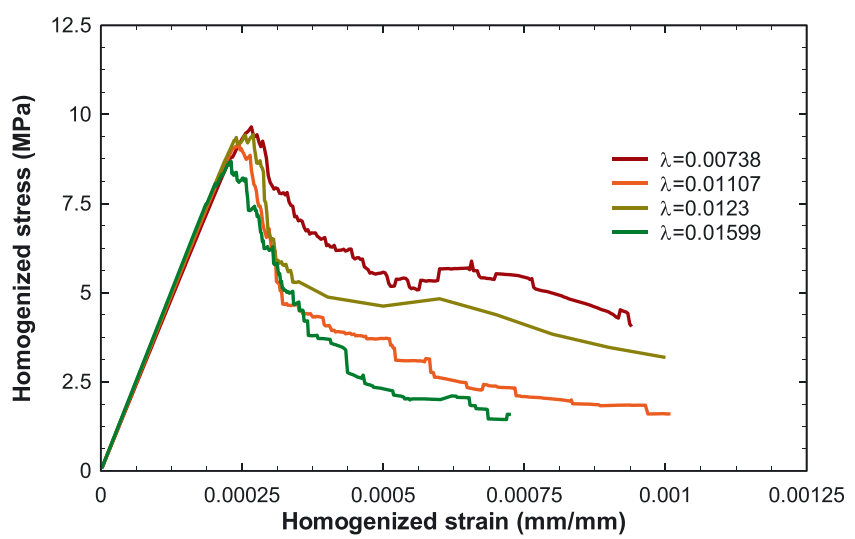

FIGURE 8 Average homogenized stress-strain corresponding to each of the different microcells [Colour figure can be viewed at wileyonlinelibrary.com]

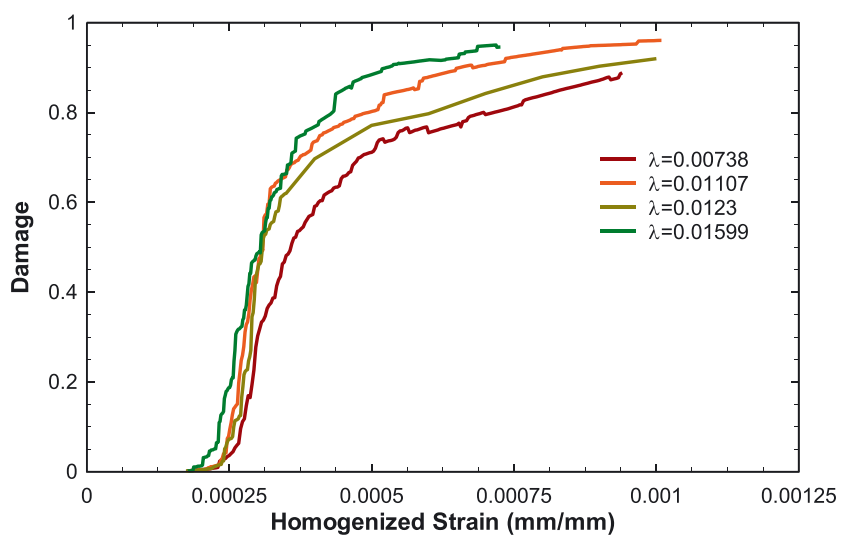

FIGURE 9 Average reference damage and homogenized strain corresponding to each of the different microcells [Colour figure can be viewed at wileyonlinelibrary.com] 


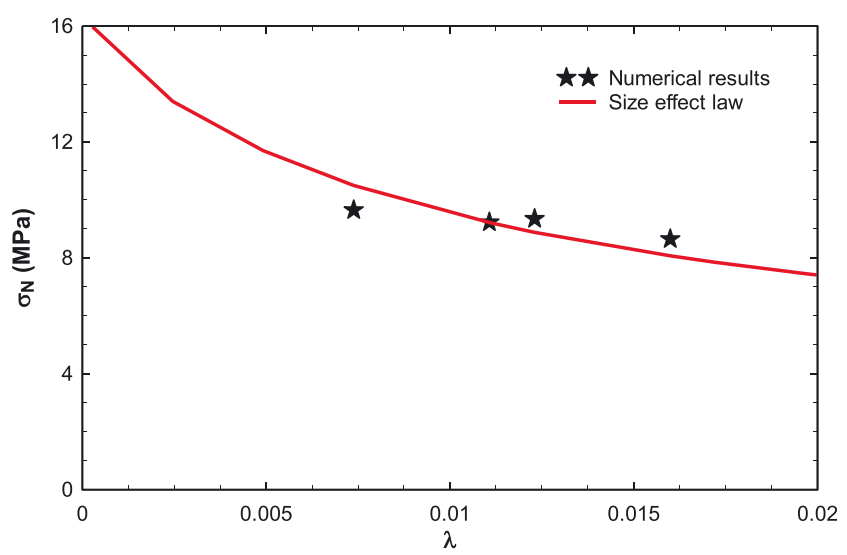

FIGURE 10 Nominal strength of simulated results fitted with size effect law [Colour figure can be viewed at wileyonlinelibrary.com]

to detect voids smaller than a certain size voxel. Hence, $l_{\text {mic }}$ corresponding to $3.0,4.5,5.0$, and 6.5 -mm range was chosen to illustrate the size effect in the UHPC.

Incorporating SDEL into the formulation addresses the size effect issues discussed by Bazant, ${ }^{36}$ Ren et al, ${ }^{31}$ and Lin et $a .^{35}$ The identification of the optimal set of constants $s^{*}$ that satisfy the nonlinear optimization problem posed in Section 3.2 is given in Table 4.

Employing SDEL within this framework allows for a more efficient and general damage scaling law. Figure 11 shows the comparison between SDEL optimal set of constants and the averaged damage evolution functions of the four different microcell geometries. SDEL captures the size effect and minimizes mesh sensitive behavior. The SDEL also captures crack initiation well but starts to deviate and over approximates the rate at which the crack grows. The microcell damage curves are highly nonlinear in nature, and future investigations will focus on limiting the rate at which the damage grows within the sigmoid. It is important to remember that the microcell damage evolution function is valid for the specific particle spacing it modeled. The SDEL allows for different microcell geometries and sizes to be considered without

TABLE 4 Optimized constants for the SDEL model

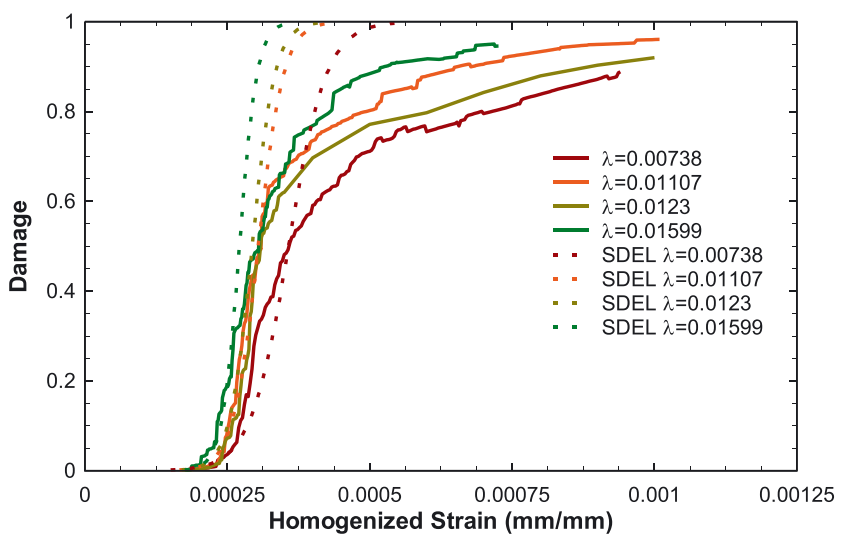

FIGURE 11 Average damage and homogenized strain corresponding to each of the different microcell sizes for the microcell calculations and SDEL [Colour figure can be viewed at wileyonlinelibrary.com] 
sacrificing the computational time of re-computing different damage evolution functions for a specific microcell. The SDEL provides a significant computational advantage and geometric flexibility compared with not incorporating a characteristic length scale. It is also worth noting that the SDEL model makes no attempt to perfectly match the post-peak residual strength. The SDEL model is an initial attempt to incorporate the overall size effects from the microcell calculations.

As discussed in Section 3.1, it is well documented in the literature that neglecting to incorporate a characteristic length scale into the damage evolution law will lead to a highly local model. Incorporating a length scale into the formulation alleviates this issue as the particle spacing is refined. The corresponding averaged homogenized stress-strain curves for each of the different microcells as calculated in Section 3 as compared with using SDEL are shown in Figure 12. As $l_{\text {mic }}$ changes for the subsequent microcells, the size effect is correctly captured. The SDEL was implemented into the macroscale continuum code that will aid in modeling the progressive damage of the macroscale problem.

\section{3 | Ballistic experiments}

To validate numerical penetration modeling at the continuum scale, a series of macroscopic ballistic experiments must be performed. The UHPC targets varied slightly in depth and thickness, but the overall diameter and geometry were constant. The diameter and average thickness were 406.4 and $31.75 \mathrm{~mm}$, respectively.

A spherical projectile was chosen for this study, and its average mass was $9.071 \mathrm{~g}$ and was $12.7 \mathrm{~mm}$ in diameter. The projectile was made of $\mathrm{S} 2$ tool-steel with a density of $7850 \mathrm{~kg} / \mathrm{m}^{3}$ and a tensile yield stress of $2000 \mathrm{MPa}$. The projectile and concrete panel dimensions and geometry are illustrated in Figure 13.

The UHPC targets were housed in a custom-built frame to allow for ease of access when setting up the targets and transitioning between shots. The impact side of the steel frame has two main lips that provide lateral and horizontal support for the cylindrical targets to sit on; these are indicated in Figure 14 by points A and B. Bolts and washers are loosely fasten to the outer steel plate face frame to allow for a snug fit in the out-of-plane direction. The frame and front plate steel face were designed to minimize edge effects during the ballistic experiments.

The ERDC ballistic facility (or fragment simulation facility) is shown in Figure 15. The firing apparatus used is a Mann Barrel system with electronic remote firing solenoid. The Mann Barrel is a heavy-walled test barrel that is fitted and mounted on rings that are concentric with the bore and allows for easy of firing. Because the S2 tool-steel is spherical and has a fairly regular geometry, a smoothbore barrel without a sabot was sufficient for this set of ballistic experiments. Two high-speed Kirana cameras were oriented on the exit face of the panel to capture the sequence of ballistic events. In order to measure impact velocities, four infrared photoelectric velocity screens located down range were connected to two chronographs to accurately measure the impact velocity. As the projectile passes through the first chronograph, the light screen is triggered, and the first and third chronographs provide the first velocity measurement. The second and fourth chronographs provide the second velocity measurement. Linear interpolation can be used to

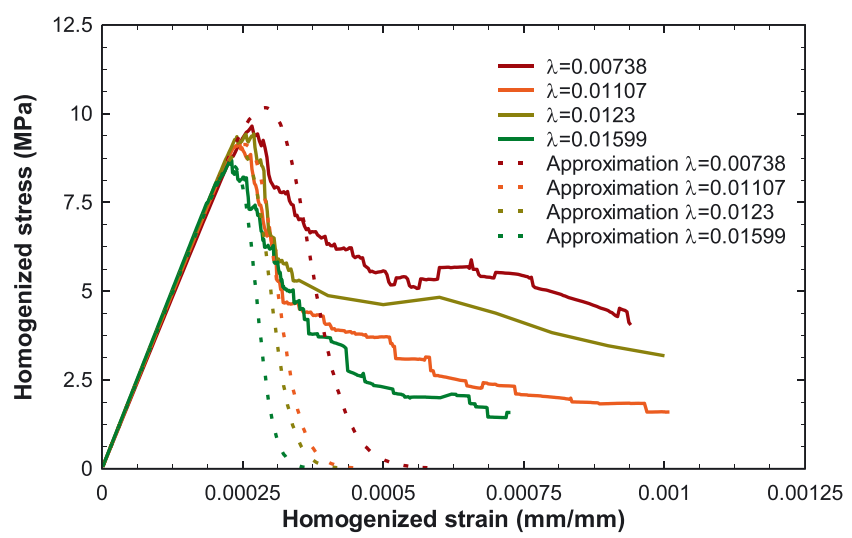

FIGURE 12 Average homogenized stress and strain corresponding to each of the different microcell sizes for the microcell calculations and stress-strain approximation using SDEL [Colour figure can be viewed at wileyonlinelibrary.com] 
FIGURE 13 Spherical projectile (12.7$\mathrm{mm}$ diameter) and the UHPC panel (406.4-mm diameter) [Colour figure can be viewed at wileyonlinelibrary.com]
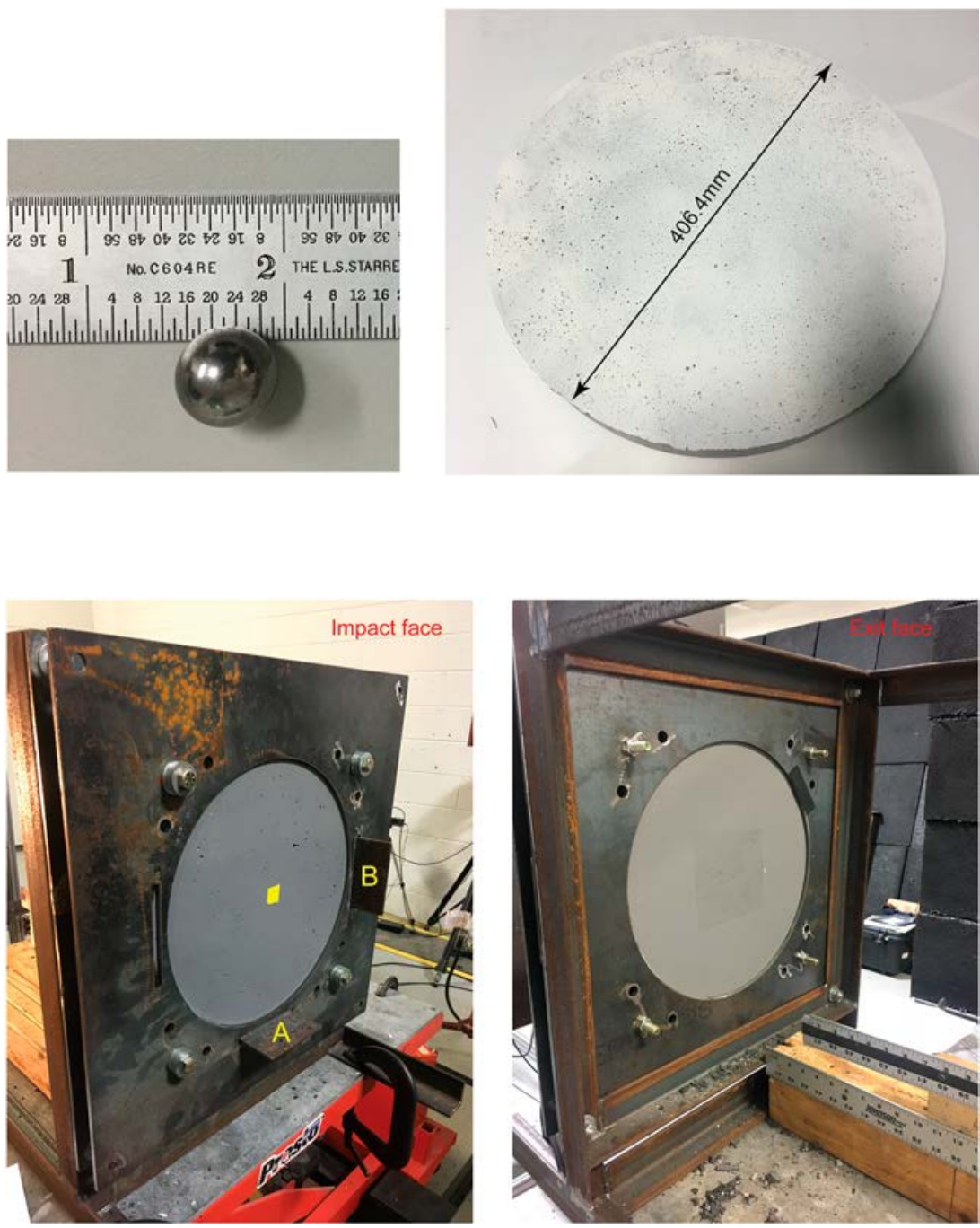

FIGURE 14 The impact face and the exit face of the UHPC targets placed in steel fixture [Colour figure can be viewed at wileyonlinelibrary.com]

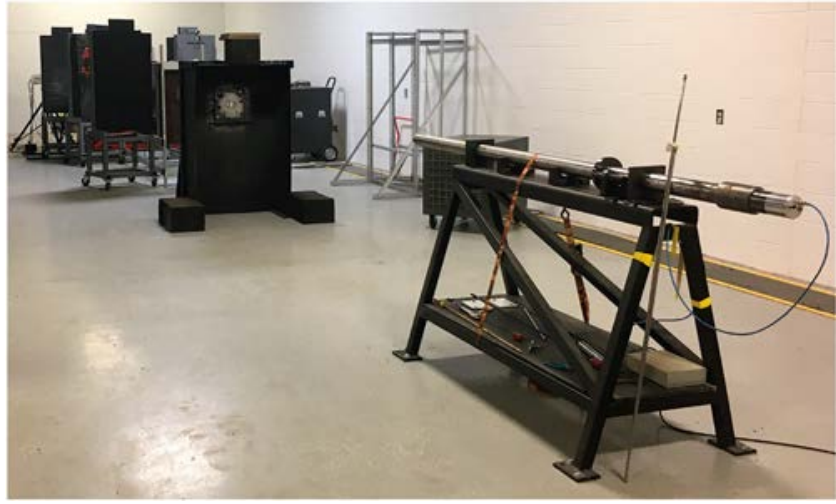

FIGURE 15 The experimental setup in the ERDC Fragmentation Simulation Facility [Colour figure can be viewed at wileyonlinelibrary. com]

determine the impact velocity because the velocity at the point of impact is based on known distances relative to the positioning of the chronograph screen.

Normal impact experiments were conducted on the UHPC targets. A series of varying impact velocity tests were conducted to determine the corresponding residual velocity of the perforation event. Seven different impact velocities were chosen to explore different velocity regimes and to understand the perforation response of the UHPC for this particular 
thickness. Different velocities were achieved by augmenting the amount of gunpowder loading onto each projectile. All of the ballistic experiments resulted in complete perforation of the target.

After impacting the UHPC panels, the projectiles did not endure significant plastic deformation. Mass loss was due to abrasion of the projectile as it was in contact with the UHPC target. For a particular impact velocity of $817 \mathrm{~m} / \mathrm{s}$, the initial spherical projectile mass was $9.071 \mathrm{~g}$ and after impact was $8.164 \mathrm{~g}$. Minor striations on the surface of the S2 tool-steel were evident and are shown in Figure 16. The impact side of the projectile into the concrete is clearly shown, and the back hemisphere of the projectile is nearly untouched. Most of the projectiles shot within the selected velocity regime were not recovered, but the few experienced similar minor striations on the impact side.

Figure 17 shows the UHPC subjected to an impact velocity of $817 \mathrm{~m} / \mathrm{s}$. This image is a snapshot of the damage experienced on the impact and exit side of the UHPC panel. Because the concrete panel is rather thin, the projectile does not experience the tunneling phase; instead, a shear cone failure is witnessed on the exit side of the target.
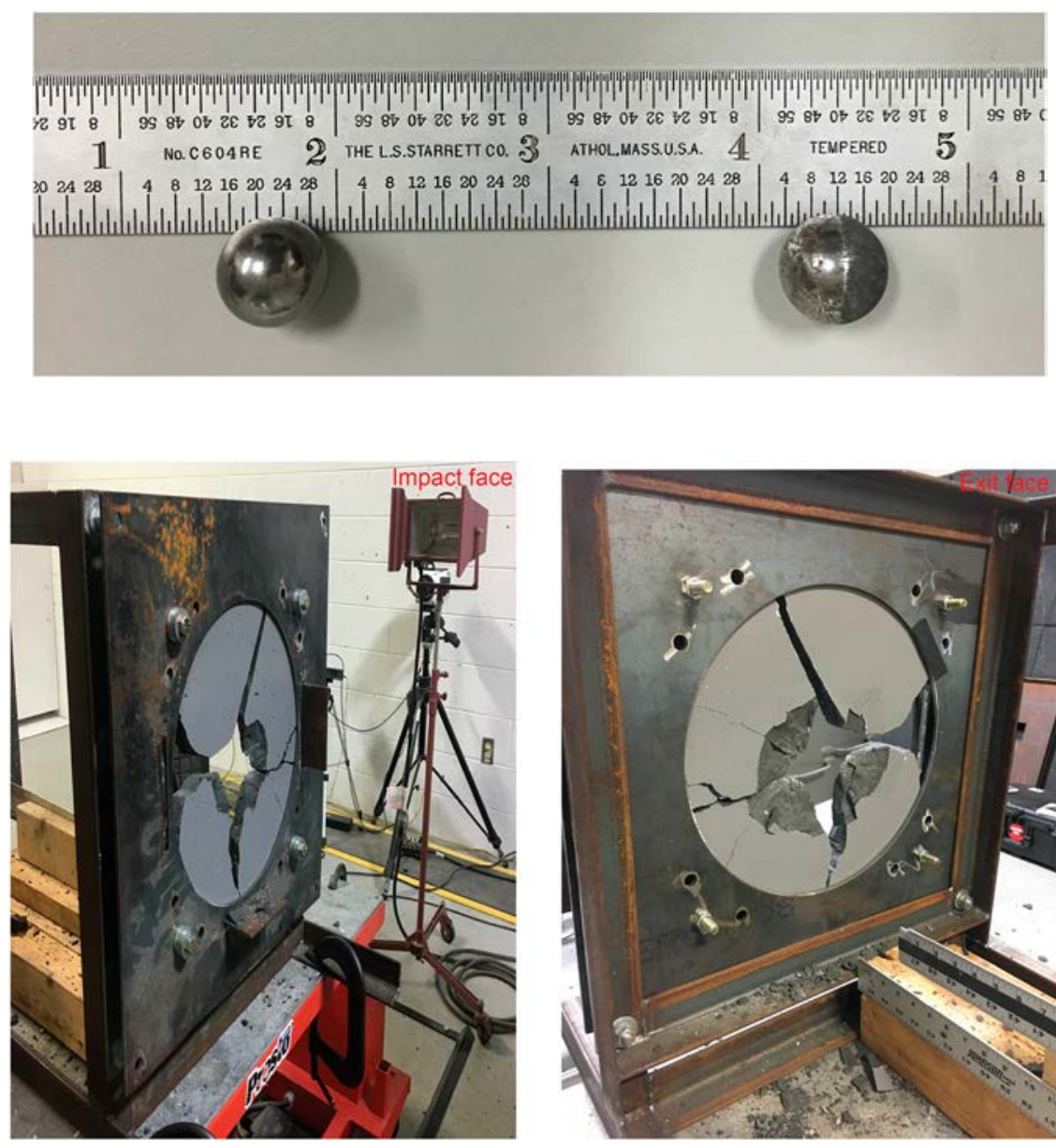

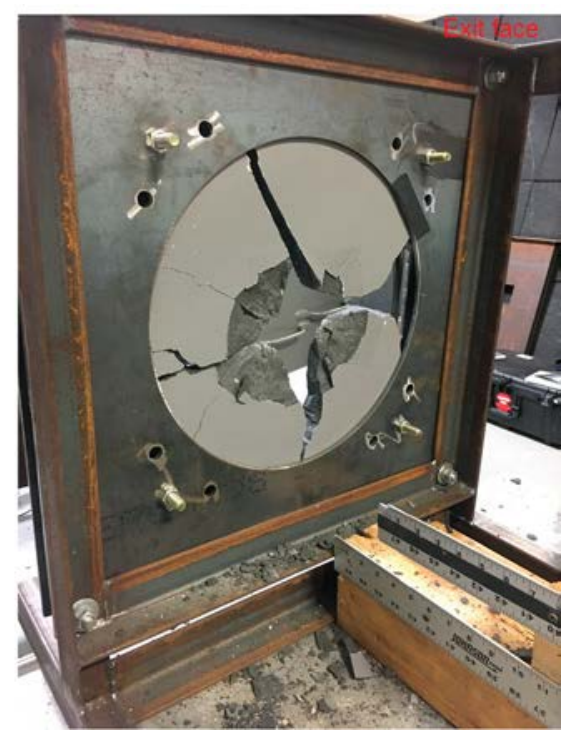

FIGURE 16 Projectile before (left) and after impact (right) the UHPC panel. The impact velocity of the spherical projectile was $817 \mathrm{~m} / \mathrm{s}$ [Colour figure can be viewed at wileyonlinelibrary.com]

FIGURE 17 Post experimental impact face and exit face of the UHPC panel. The impact velocity for this experiment was $817 \mathrm{~m} / \mathrm{s}$ [Colour figure can be viewed at wileyonlinelibrary.com]

TABLE 5 Experimental impact and residual velocities of spherical projectile perforating the UHPC targets

\begin{tabular}{lccc} 
Target Thickness, $\mathbf{m m}$ & Target Mass, kg & Impact Velocity, m/s & Residual Velocity, m/s \\
\hline 32.31 & 10.71 & 610 & 53 \\
31.80 & 10.54 & 613 & 72 \\
29.14 & 9.66 & 689 & 170 \\
\hline 31.55 & 10.46 & 817 & 236 \\
31.10 & 10.31 & 903 & 330 \\
\hline 29.29 & 9.71 & 992 & 456 \\
\hline 30.28 & 10.04 & 1112 & 556 \\
\hline
\end{tabular}


A summary of the ballistic experiments is shown in Table 5; the thickness and weight of each target are reported in the table along with the impact and residual velocities. The following section will model the range of impact velocities performed in the experiments using the SDEL model.

\section{4 | Continuum analysis}

The numerical simulations conducted in this study were based on hierarchical multiscale modeling in which microcell simulations simulating the fracture of the porous UHPC matrix microstructure are conducted a priori. The damage vs homogenized strain response from the MIDM energy bridging produces a general SDEL that can be employed in the penetration numerical analysis conducted at the continuum level.

The continuum analyses were performed utilizing NMAP, which is a three-dimensional RKPM-based code (Chi et $\mathrm{al}^{47}$ ). NMAP naturally models large deformations that include material fragmentation of the experiments described in the previous section because the RKPM framework has no need for ad hoc failure models such as element erosion that are necessary for the finite element method to model perforation (Guan et $\mathrm{al}^{48}$ and Yreux and $\mathrm{Chen}^{49}$ ). For this class of problems, naturally stabilized nodal integration (Hillman and Chen, ${ }^{50}$ ) is introduced to reduce spatial instabilities that govern the effects of debris and fragmentation experienced in these dynamic events. Quasi-linear kernels on the support are proposed by Yreux and Chen, ${ }^{49}$ to ensure the stability of the model.

The concrete model for this study employs the AFC model (Adley et $\mathrm{al}^{37}$ ). A brief general description of the AFC model is provided, but the full description and the formulation are omitted for brevity. The AFC model governing the simulation of concrete penetration by projectiles is based on a three-invariant plasticity model. The model simulates hydrostatic crushing, material yielding, and damage among other irreversible thermodynamic processes. The hydrostatic behavior is defined by three different portions, ie, linear elastic, hydrostatic crushing, and linear locking. The low pressure region is governed by the linear-elastic portion where the bulk response is defined by the initial crushing pressure and volumetric strain. The hydrostatic crushing is the nonlinear region due to voids collapsing and crushing, which is approximated by a third-order polynomial. Lastly, in the locking region, the material is considered fully densified, and a linear bulk modulus governs the higher pressure volumetric response. The AFC model has been applied to several investigations involving the simulation of projectiles into cementitious materials. For a more in-depth discussion, the details of the model can be found in the literature (Adley et al, ${ }^{37}$ Sherburn et al, ${ }^{26,27}$ Nordendale et al, ${ }^{22} \mathrm{Chan}$ dler et $\mathrm{al}^{51}$ ).

A brief description of the links between the AFC model and SDEL is summarized below. The AFC failure surface of the UHPC is described as the deviatoric response that is dependent on the pressure, strain rate, and damage. The failure surface in compression is described as

$$
S_{Y}^{\text {comp }}=\left(C_{1}-\left(C_{2}+\left(C_{1}-C_{2}\right) d^{-}\right) e^{-A_{n} P}+C_{4} P\right)\left(1+C_{3} \ln \left(\dot{\varepsilon}_{n}\right)\right)
$$

where $C_{1}, C_{2}, C_{3}, C_{4}$, and $A_{n}$ are constants greater than zero, $\mathrm{P}$ is the pressure, and a positive sign convention denotes compression. $d^{-}$is the compressive scalar damage term that goes from 0.0 to 1.0 , and $\dot{\varepsilon}_{n}$ is a normalized strain rate. The normalized strain rate is defined by

$$
\dot{\varepsilon}_{n}=\frac{\dot{\varepsilon}}{\dot{\varepsilon}_{0}}
$$

where $\dot{\varepsilon_{0}}$ is a reference strain rate. The reference strain rate for this material was chosen to be $0.0001 \mathrm{~s}^{-1}$. The tensile failure surface is defined as

$$
S_{y}^{\text {tens }}=\left(C_{1}-\left(C_{2}+\left(C_{1}-C_{2}\right) d^{-}\right)\right)\left(1+C_{3} \ln \left(\dot{\varepsilon}_{n}\right)\right) \frac{T_{\max }\left(1-d^{+}\right)+P}{T_{\max }\left(1-d^{+}\right)}
$$

where $T_{\max }$ is the maximum allowable tensile pressure. The compressive scalar damage, $d^{-}$, is defined by

$$
d^{-}=\sum\left[\frac{\varepsilon_{p c}}{P D_{1}}+\frac{\mu_{p c}}{1.5 C_{9}}\right]
$$


where $D_{1}$ is a material constant, and $\varepsilon_{p c}$ and $\mu_{p c}$ are the plastic strain increment under compression and volumetric strain increment under compression, respectively.

To approximate the HFE within the microcell, a modified sigmoid was fit to the nonlinear damage evolution form using the optimal set of constants $\boldsymbol{s}^{*}$ described in Table 4 . The tensile scalar damage, $d^{+}$, is represented by the SDEL referenced in Section 3.1:

$$
d^{+} \lambda \mathrm{e}^{-}=\frac{1}{1+v e^{-\lambda \chi \mathrm{e}^{-}-\mathrm{e}_{i}^{-}}}, \quad 0 \leq d^{+} \leq 1 .
$$

Table 6 summarizes the constants used in the AFC model for the continuum analysis in this study.

Figure 18 shows the geometry and the numerical model setup for the validation study of the ballistic experiments for the UHPC material subjected to a S2 tool-steel projectile with varying initial velocities. The particle spacing of the concrete panel is radially biased with the maximum spacing near the boundary of the target and a nearly uniform microcell

TABLE 6 AFC constants used for the UHPC

\begin{tabular}{|c|c|}
\hline Parameter & Value \\
\hline Density $\left(\mathrm{kg} / \mathrm{m}^{3}\right)$ & 2555.7 \\
\hline Shear modulus (MPa) & 18457.0 \\
\hline $\mathrm{C}_{1}(\mathrm{MPa})$-failure surface constant & 957.8 \\
\hline $\mathrm{C}_{2}(\mathrm{MPa})$-failure surface constant & 888.2 \\
\hline $\mathrm{C}_{3}$-failure surface constant & 0.01 \\
\hline $\mathrm{C}_{4}$-failure surface constant & 0.001 \\
\hline $\mathrm{C}_{5}(\mathrm{MPa})$ - failure surface constant & 792.88 \\
\hline $\mathrm{C}_{6}(\mathrm{MPa})$ - pressure where crushing begins & 172.37 \\
\hline $\mathrm{C}_{7}$-volumetric strain at crushing & 0.00781 \\
\hline $\mathrm{C}_{8}(\mathrm{MPa})$-locking modulus & 45039.0 \\
\hline $\mathrm{C}_{9}$-volumetric strain at locking & 0.10094 \\
\hline $\mathrm{K}_{1}(\mathrm{MPa})$ - hydrostatic compression constant & 7919.2 \\
\hline $\mathrm{K}_{2}(\mathrm{MPa})$-hydrostatic compression constant & -29206.0 \\
\hline $\mathrm{K}_{3}(\mathrm{MPa})$-hydrostatic compression constant & 187100.0 \\
\hline $\mathrm{D}_{1}\left(\mathrm{MPa}^{-1}\right)$-damage constant & 0.000406 \\
\hline $\mathrm{A}_{\mathrm{N}}\left(\mathrm{MPa}^{-1}\right)$ - failure surface constant & 0.002329 \\
\hline $\mathrm{T}_{\max }(\mathrm{MPa})$ - maximum allowable tensile pressure & 6.89 \\
\hline
\end{tabular}

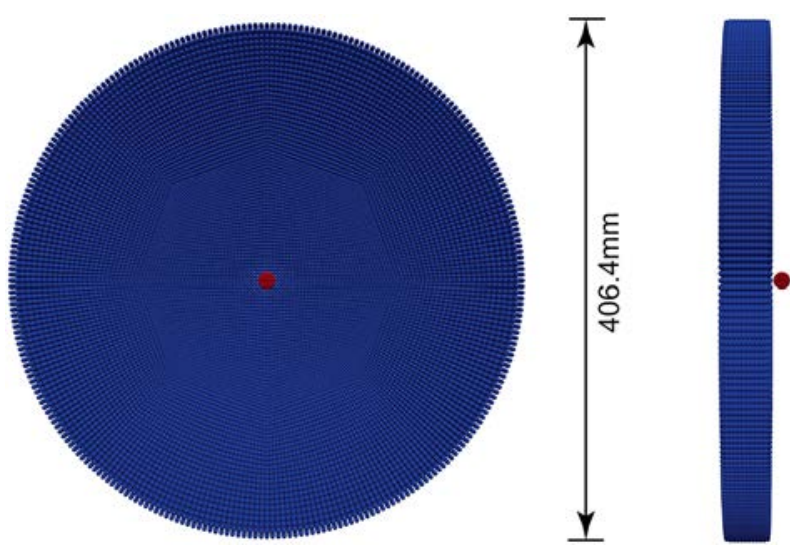

FIGURE 18 Geometry and discretization of spherical projectile impacting the UHPC panel [Colour figure can be viewed at wileyonlinelibrary.com] 
spacing in the zone of the penetration event. Figure 19 displays a detailed view of the biased particle spacing. Because the target is cylindrical, ensuring that the damage law scales with particle spacing to avoid size effect and mesh sensitive results is alleviated through SDEL. Near the center of the target, a 3.0-mm particle spacing is used to discretize the region and radially outward approaches a spacing of $4.5 \mathrm{~mm}$. All of the continuum simulations were full 3D and therefore had no symmetry planes.

The NMAP model was developed for a S2 tool-steel projectile and was discretized using 1933 nodes. For simplicity, the spherical projectile was approximated as a rigid material because the experimental projectile had little plastic deformation. The UHPC target contained approximately 150000 nodes and used the AFC model parameters described in Table 6. In order to validate the ballistic experimental results, the UHPC target was subjected to impact striking velocities that spanned the experimental ranges. The 31.75-mm-thick target had initial striking velocities that ranged from

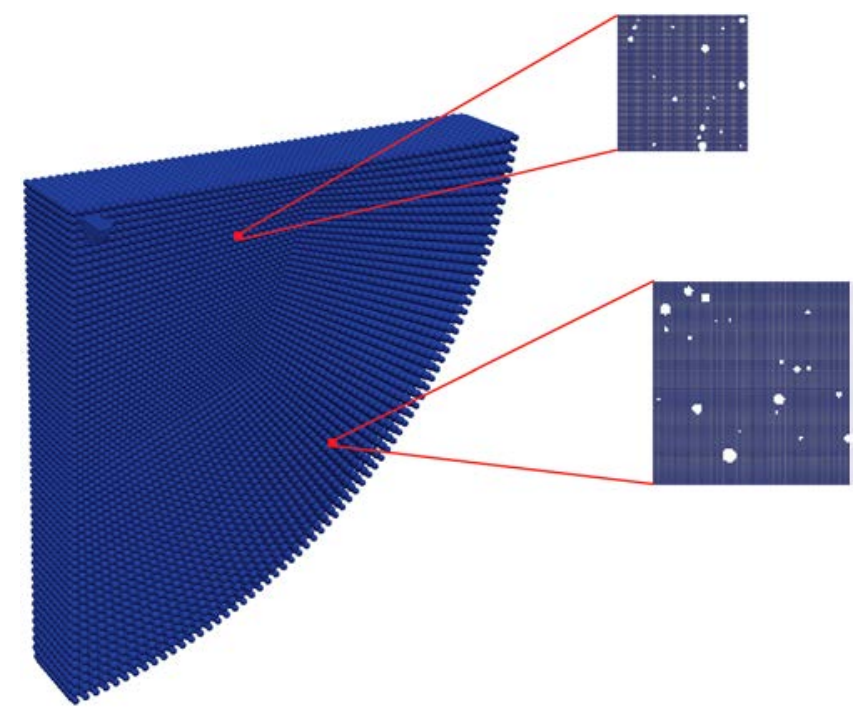

FIGURE 19 Radially expanding particle spacing along with discretized microcell sizes $3.0 \times 3.0$ and $4.5 \times 4.5 \mathrm{~mm}^{2}$ [Colour figure can be viewed at wileyonlinelibrary.com]

FIGURE 20 NMAP damage contours for the UHPC panel impacted by the spherical projectile at $820 \mathrm{~m} / \mathrm{s}$ [Colour figure can be viewed at wileyonlinelibrary. com]
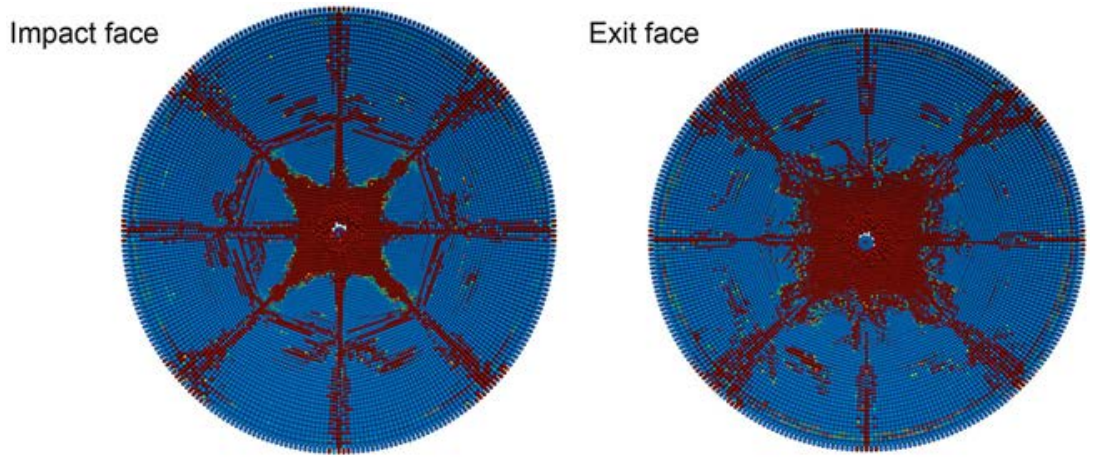

Cross Section

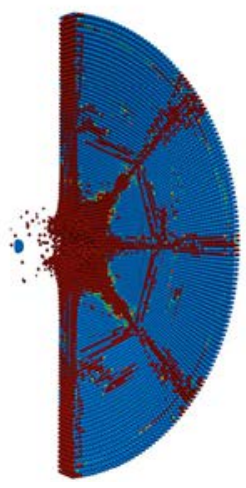

Side Profile 
400 to $1200 \mathrm{~m} / \mathrm{s}$. A total of 81 continuum analyses were conducted on the $31.75-\mathrm{mm}$-thick target with an initial velocity of $400 \mathrm{~m} / \mathrm{s}$ and incremented by $10 \mathrm{~m} / \mathrm{s}$ until the final impact velocity was achieved.

Figure 20 gives a snapshot of the steel projectile impacting the UHPC panel with an initial velocity of $820 \mathrm{~m} / \mathrm{s}$. The damage contours agree reasonably with the analogous experiment displayed in Figure 17. The snapshot shown in Figure 20 is taken when the projectile is exiting the back face of the panel. The ballistic experiments show the UHPC panel segmenting into several pieces similar to what is observed in the NMAP calculations. As the projectile perforates the concrete material, the back side of the concrete is loaded in tension, and similarly, a shear cone failure is observed. The computed craters from the numerical simulations were not compared with the craters from the ballistic experiments because the full cratering process takes much longer than the times used for the continuum simulations, hence comparing general qualitative damage features and specific exit velocities was the focus of this study. Figure 21 shows

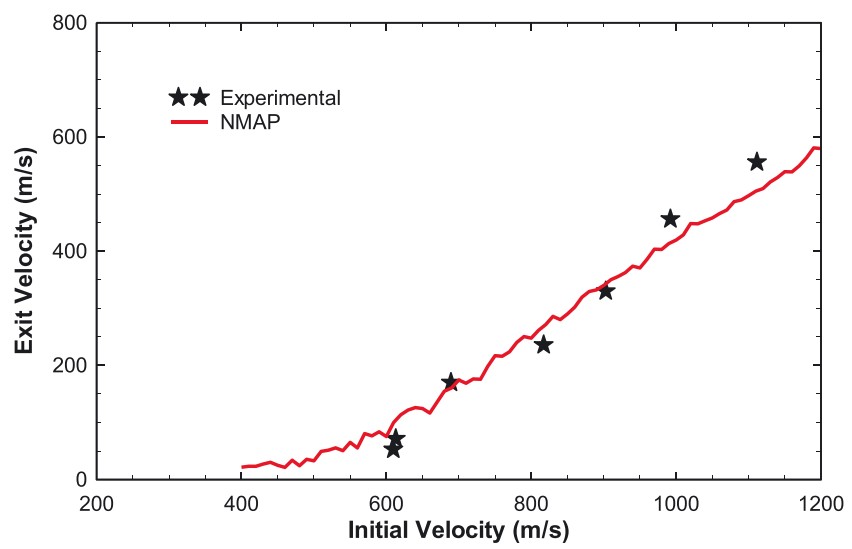

FIGURE 21 Experimental and NMAP residual velocities for the UHPC panel [Colour figure can be viewed at wileyonlinelibrary.com]

TABLE 7 Experimental velocity reductions and kinetic energy reductions

\begin{tabular}{|c|c|c|c|c|}
\hline Nominal Target Thickness, mm & Impact Velocity, m/s & Residual Velocity, m/s & Velocity Reduction, $\mathrm{m} / \mathrm{s}$ & KE Reduction, J \\
\hline 31.75 & 613 & 72 & 541 & 1560 \\
\hline 31.75 & 689 & 170 & 519 & 1877 \\
\hline 31.75 & 817 & 236 & 581 & 2575 \\
\hline 31.75 & 1112 & 556 & 556 & 3904 \\
\hline
\end{tabular}

TABLE 8 Numerical velocity reductions and kinetic energy reductions. The \% error columns are comparisons to the analogous experiment

\begin{tabular}{|c|c|c|c|c|c|c|}
\hline $\begin{array}{l}\text { Nominal Target } \\
\text { Thickness, mm }\end{array}$ & $\begin{array}{l}\text { Impact } \\
\text { Velocity, } \mathrm{m} / \mathrm{s}\end{array}$ & $\begin{array}{l}\text { Residual } \\
\text { Velocity, m/s }\end{array}$ & $\begin{array}{l}\text { Velocity } \\
\text { Reduction, m/s }\end{array}$ & $\begin{array}{l}\text { \% Error (Velocity } \\
\text { Reduction) }\end{array}$ & $\begin{array}{l}\text { KE } \\
\text { Reduction } \\
\text { (J) }\end{array}$ & $\begin{array}{l}\text { \% Error (KE } \\
\text { Reduction) }\end{array}$ \\
\hline 31.75 & 610 & 100 & 510 & $6 \%$ & 1524 & $2 \%$ \\
\hline 31.75 & 690 & 160 & 530 & $-2 \%$ & 1896 & $-1 \%$ \\
\hline 31.75 & 900 & 340 & 560 & $2 \%$ & 2923 & $2 \%$ \\
\hline 31.75 & 990 & 413 & 577 & $-8 \%$ & 3408 & $-4 \%$ \\
\hline 31.75 & 1110 & 505 & 605 & $-9 \%$ & 4113 & $-5 \%$ \\
\hline
\end{tabular}


that the NMAP calculations agree reasonably with the ballistic experiments. The numerical results closely follow the exit velocity up to $900 \mathrm{~m} / \mathrm{s}$ (see Table 8) and start underpredicting the exit velocities greater than $1000 \mathrm{~m} / \mathrm{s}$.

Another useful way to compare the experimental data to the numerical results is by comparing velocity reduction and kinetic energy reduction. The experimental values are shown in Table 7, and the numerical values are shown in Table 8 . The $\%$ error values in Table 8 are calculated by comparing the analogous experiment with the numerical result. The numerical results for the 31.75-mm-thick targets were either slightly above or slightly below the experimental result in line with the trend shown in Figure 21.

\section{I CONCLUSIONS}

A suite of static and dynamic physical experiments were conducted to characterize the UHPC material. The micro-CT scans provided a statistical representative microstructure that included the pore characteristics of the concrete material. The experimental data from the micro-CT characterization was used to produce a SDEL that is informed by microscale calculations. NMAP-M calculations were performed to develop a SDEL that is implemented into the macroscale calculations. The generalized SDEL alleviates using a damage law for a particular microcell and allows for several different particle spacing's to capture the proper energy dissipation and mitigate size effect dependency. Results of ballistic experiments at the continuum level are in reasonable agreement with NMAP-continuum analysis.

\section{ACKNOWLEDGEMENTS}

The experiments described and the resulting data presented herein, unless otherwise noted, were funded under PE 61102, Project T22 "Material Modeling for Force Protection," Task 02 managed and executed at the US Army Engineer Research and Development Center. Permission to publish was granted by the Director, Geotechnical and Structures Laboratory, US Army Engineer Research and Development Center. Simulations were partly performed on the Department of Defense Super Computing Resource high-performance computers.

\section{REFERENCES}

1. White MP. Effects of Impact and Explosion. Washington D.C: Office of Scientific Research and Development; 1946.

2. Kennedy RP. A review of procedures for the analysis and design of concrete structures to resist missile impact effects. Nucl Eng Des. 1976;37(2):183-203.

3. Backman ME, Goldsmith W. The mechanics of penetration of projectiles into targets. Int J Eng Sci. 1978;16(1):1-99.

4. Ben-Dor G, Dubinsky A, Elperin T. Analytical engineering models for predicting high speed penetration of hard projectiles into concrete shields: a review. Int J of Damage Mech. 2014;24(1):76-94.

5. Luk V, Forrestal M. Penetration into semi-infinite reinforced-concrete targets with spherical and ogival-nose projectiles. Int J Impact Eng. 1987;6(4):291-301.

6. Luk V, Forrestal M. Comment on "Penetration into semi-infinite reinforced-concrete targets with spherical and ogival-nose projectiles. (International Journal of Impact Engineering., vol. 6, pp. 291-301, 1987)”. Int J Impact Eng. 1989;8(1):83-84.

7. Frew D, Forrestal M, Cargile J. The effect of concrete target diameter on projectile deceleration and penetration depth. Int J Impact Eng. 2006;32(10):1584-1594.

8. Hanchak S, Forrestal M, Young E, Ehrgott J. Perforation of concrete slabs with $48 \mathrm{MPa}(7 \mathrm{ksi})$ and $140 \mathrm{MPa}$ (20 ksi) unconfined compressive strengths. Int J Impact Eng. 1992;12(1):1-7.

9. Máca P, Sovják R, Konvalinka P. Mix design of UHPFRC and its response to projectile impact. Int J Impact Eng. 2014;63:158-163.

10. Wu H, Fang Q, Gong J, Liu J, Zhang J, Gong Z. Projectile impact resistance of corundum aggregated UHP-SFRC. Int J Impact Eng. 2015a;84:38-53.

11. Wu H, Fang Q, Chen X, Gong Z, Liu J. Projectile penetration of ultra-high performance cement based composites at 510-1320 m/s. Construct Build Mater. 2015b;74(15):188-200.

12. Peng Y, Wu H, Fang Q, Liu JZ, Gong ZM. Residual velocities of projectiles after normally perforating the thin ultra-high performance steel fiber reinforced concrete slabs. Int J Impact Eng. 2016;97:1-9. 
13. Johnson GR, Stryk RA. Eroding interface and improved tetrahedral element algorithms for high-velocity impact computations in three dimensions. Int J Impact Eng. 1987;5(1-4):411-421.

14. Belytschko T, Lin A. A three-dimensional impact-penetration algorithm with erosion. Int J Impact Eng. 1987;5(1-4):111-127.

15. Rajput A, Iqbal MA, Bhargava P. Experimental and numerical study of concrete targets under high rate loading. Procedia Eng. 2017;173:130-137.

16. Zhang S, Wu H, Zhang X, Liu J, Huang F. High-velocity penetration of concrete targets with three types of projectiles: experiments and analysis. Latin Am J Solids Struct. 2017;14(9):1614-1628.

17. Smith J, Cusatis G, Pelessone D, Landis E, O'Daniel J, Baylot J. Discrete modeling of ultra-high-performance concrete with application to projectile penetration. Int J Impact Eng. 2014;65:13-32.

18. Smith J, Cusatis G. Numerical analysis of projectile penetration and perforation of plain and fiber reinforced concrete slabs. Int J Numer Anal Meth Geomech. 2016;41:315-337.

19. Silling SA, Askari E. A meshfree method based on the peridynamic model of solid mechanics. Comput Struct. 2005;83(17-18):1526-1535.

20. Diehl P, Bubler M, Pfluger D, et al. Extraction of fragments and waves after impact damage in particle-based simulations. In: Griebel M, Schweitzer M, eds. Meshfree Methods for Partial Differential Equations VIII. Lecture Notes in Computational Science and Engineering. Vol.115 Cham: Springer; 2017.

21. Kala J, Hušek M. Improved element erosion function for concrete-like materials with the SPH method. Shock Vib. 2016. https://doi.org/ 10.1155/2016/4593749;2016, Article ID 4593749:13 pages, 2016-13.

22. Nordendale NA, Heard WF, Sherburn JA, Basu PK. A comparison of finite element analysis to smooth particle hydrodynamics for application to projectile impact on cementitious material. Computational Particle Mech. 2016;3(1):53-68. https://doi.org/10.1007/s40571-0150092-1

23. Chen JS, Hu W, Puso MA, Wu Y, Zhang X. Strain smoothing for stabilization and regularization of Galerkin meshfree method. Lecture Notes in Computational Science and Eng. 2006;57:57-76.

24. Chen JS, Chi SW, Lee CH, Lin SP, Marodon C, Roth MJ. A Multiscale Meshfree Approach for Modeling Fragment Penetration into UltraHigh-Strength Concrete. Technical Report ERDC/GSL TR-11-35. Vicksburg, MS: U.S. Army Engineer Research and Development Center; 2011.

25. Chi SW, Lee CH, Chen JS, Guan PC. A level set enhanced natural kernel contact algorithm for impact and penetration modeling. Int $J$ Numer Methods Eng. 2015;102(3-4):839-866.

26. Sherburn JA, Hammons MI, Roth MJ. Modeling finite thickness slab perforation using a coupled Eulerian-Lagrangian approach. Int $J$ Solids Struct. 2014;51(25-26):4406-4413.

27. Sherburn JA, Roth MJ, Chen JS, Hillman M. Meshfree modeling of concrete slab perforation using a reproducing kernel particle impact and penetration formulation. Int J of Impact Eng. 2015;86:96-110.

28. Guedes JM, Kikuchi N. Preprocessing and postprocessing for materials based on the homogenization method with adaptive finite element methods. Comput Methods Appl Mech Eng. 1990;83(2):143-198.

29. Cheng, C.H. Modeling of elasto-plastic behavior for composite materials using homogenization method, PhD dissertation, University of Michigan, 1992.

30. Fish J, Shek K, Pandheeradi M, Shephard MS. Computational plasticity for composite structures based on mathematical homogenization: theory and practice. Comput Methods Appl Mech Eng. 1997;148(1-2):53-73.

31. Ren X, Chen JS, Li J, Slawson TR, Roth MJ. Micro-cracks informed damage models for brittle solids. Int J Solids Struct. 2011;48(10):1560-1571.

32. Pijaudier-Cabot G, Bazant ZP. Nonlocal Damage Theory, Center for Concrete and Geomaterials. Evanston, IL., Report No. 86-8/428n: Northwestern University; Aug. 1986.

33. Bazant ZP, Jirasek M. Nonlocal integral formulations of plasticity and damage: survey of progress. $J$ Eng Mech. 2002;128(11):1119-1149.

34. Jirasek M. Non-local damage mechanics with application to concrete. Failure, Revue Française de Génie Civil. 2004;8(5-6):683-707.

35. Lin SP, Chen JS, Liang S. A damage analysis for brittle materials using stochastic microstructural information. Comput Mech. 2016;57(3):371-385.

36. Bazant ZP. Size effect in blunt fracture: concrete, rock, metal. J Eng Mech. 1984;110(4):518-535.

37. Adley MD, Frank AO, Danielson KT, Akers SS, O'Daniel JL. The Advanced Fundamental Concrete (AFC) model. Vicksburg, MS, Technical Report ERDC/GSL TR-10-51: U.S. Army Engineer Research and Development Center; 2010.

38. Liu WK, Jun S, Zhang YF. Reproducing kernel particle methods. Int J Numer Methods Fluids. 1995;20(8-9):1081-1106.

39. Chen JS, Pan C, Wu CT, Liu WK. Reproducing kernel particle methods for large deformation analysis of nonlinear structures. Comput Methods Appl Mech Eng. 1996;139:49-74.

40. Fleming M, Chu YA, Moran B, Belytschko T. Enriched element-free Galerkin methods for crack tip fields. Int J Numer Methods Eng. 1997;40(8):1483-1504

41. Moes N, Belytschko T. Extended finite element method for cohesive crack growth. Eng Fract Mech. 2002;69(7):813-833. 
42. O'Neil, E.F. 2008. On engineering the microstructure of high-performance concretes to improve strength, rheology, toughness, and frangibility. PhD dissertation, Northwestern University, 2008.

43. Williams EM, Graham SS, Reed PA, Rushing TS. Laboratory Characterization of Cor-Tuf Concrete with and without Steel Fibers. Technical Report ERDC/GSL TR-09-22. Vicksburg, MS: U.S. Army Engineer Research and Development Center; 2009.

44. Martin BE, Heard WF, Loeffler CM, Nie X. Specimen size and strain rate effect on the compressive behavior of concrete. Exp Mech. 2018;58(2):357-368.

45. Sherburn J, Heard B, Williams B, Sparks P. A multiscale meshfree approach to modeling damage of an ultra-high performance concrete. Int J Multiscale Comput Eng. 2018;16(2):143-161.

46. Hillerborg A, Modeer M, Petersson P. Analysis of crack formation and crack growth in concrete by means of fracture mechanics and finite elements. Cem Concr Res. 1976;6(6):773-782.

47. Chi, S.W., Lee, C.H., Chen, J.S., Roth, M.J., and Slawson, T.R. User's manual for non-linear meshfree analysis program (NMAP), version 1.0. U.S. Army Engineer Research and Development Center, Vicksburg, MS, Technical Report ERDC/GSL TR-12-36, 2012.

48. Guan PC, Chi SW, Chen JS, Slawson TR, Roth MJ. Semi-Lagrangian reproducing kernel particle method for fragment-impact problems. Int J Impact Eng. 2011;38(12):1033-1047.

49. Yreux E, Chen JS. A quasi-linear reproducing kernel particle method. Int J Numer Methods Eng. 2017;109(7):1045-1064.

50. Hillman M, Chen JS. An accelerated, convergent, and stable nodal integration in Galerkin meshfree methods for linear and nonlinear mechanics. Int J Numer Methods Eng. 2016;107(7):603-630.

51. Chandler MQ, Sherburn JA, Allison PG, et al. Application of bio-inspired nanocomposites for enhancing impact resistance of cementitious materials. Int J of Impact Eng. 2017;110:171-180. https://doi.org/10.1016/j.ijimpeng.2017.02.013 


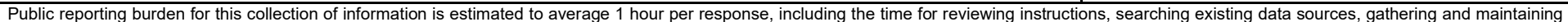

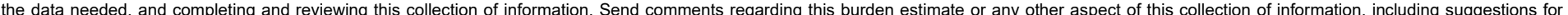

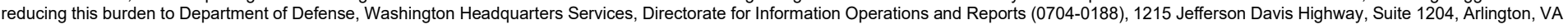

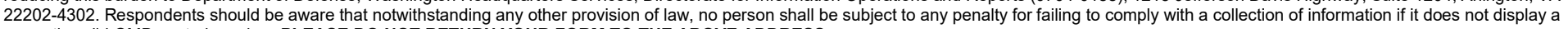
currently valid OMB control number. PLEASE DO NOT RETURN YOUR FORM TO THE ABOVE ADDRESS.
1. REPORT DATE (DD-MM-YYYY)
September 2021

4. TITLE AND SUBTITLE

Penetration Modeling of Ultra-High Performance Concrete using Multiscale Meshfree Methods

\section{AUTHOR(S)}

Paul A. Sparks, Jesse A. Sherburn, William F. Heard, and Brett A. Williams

\section{DATES COVERED (From - To)}

\section{5a. CONTRACT NUMBER}

5b. GRANT NUMBER

5c. PROGRAM ELEMENT NUMBER

5d. PROJECT NUMBER

5e. TASK NUMBER

5f. WORK UNIT NUMBER

8. PERFORMING ORGANIZATION REPORT NUMBER

ERDC/GSL MP-21-6

Geotechnical and Structures Laboratory

U.S. Army Engineer Research and Development Center

3909 Halls Ferry Road

Vicksburg, MS 39180

9. SPONSORING / MONITORING AGENCY NAME(S) AND ADDRESS(ES)

U.S. Army Corps of Engineers

Washington, DC 20314

\section{DISTRIBUTION / AVAILABILITY STATEMENT}

Approved for public release; distribution is unlimited.

\section{SUPPLEMENTARY NOTES}

This article was originally published online in the International Journal of Numerical and Analytical Methods in Geomechanics on 10 October 2019. The experiments described and the resulting data presented herein were funded under PE 61102, Project T22 "Material Modeling for Force Protection," Task 02, managed and executed at the US Army Engineer Research and Development Center (ERDC).

\section{ABSTRACT}

Terminal ballistics of concrete is of extreme importance to the military and civil communities. Over the past few decades, ultra-high performance concrete (UHPC) has been developed for various applications in the design of protective structures because UHPC has an enhanced ballistic resistance over conventional strength concrete. Developing predictive numerical models of UHPC subjected to penetration is critical in understanding the material's enhanced performance. This study employs the advanced fundamental concrete (AFC) model, and it runs inside the reproducing kernel particle method (RKPM)-based code known as the nonlinear meshfree analysis program (NMAP). NMAP is advantageous for modeling impact and penetration problems that exhibit extreme deformation and material fragmentation. A comprehensive experimental study was conducted to characterize the UHPC. The investigation consisted of fracture toughness testing, the utilization of nondestructive microcomputed tomography analysis, and projectile penetration shots on the UHPC targets. To improve the accuracy of the model, a new scaled damage evolution law (SDEL) is employed within the microcrack informed damage model. During the homogenized macroscopic calculation, the corresponding microscopic cell needs to be dimensionally equivalent to the mesh dimension when the partial differential equation becomes ill posed and strain softening ensues. Results of numerical investigations will be compared with results of penetration experiments.

\section{SUBJECT TERMS}

Constitutive modeling, multiscale modeling, penetration modeling, reproducing kernel particle method, ultra-high performance concrete

\section{SECURITY CLASSIFICATION OF:}

\section{a. REPORT}

Unclassified

\section{b. ABSTRACT \\ Unclassified}

\section{c. THIS PAGE}

Unclassified
17. LIMITATION OF ABSTRACT

UU
18. NUMBER OF PAGES

29 19a. NAME OF RESPONSIBLE PERSON

19b. TELEPHONE NUMBER (include area code) 